\title{
LOS USOS DEL CANON EUROPEO EN LA JURISPRUDENCIA DEL TRIBUNAL CONSTITUCIONAL: UNA MUESTRA DEL PROCESO DE ARMONIZACIÓN EUROPEA EN MATERIA DE DERECHOS FUNDAMENTALES ${ }^{1}$
}

\author{
ARGELIA QUERALT JIMÉNEZ \\ Profesora Titular interina de Derecho Constitucional \\ Universidad de Barcelona
}

SUMARIO

I. El proceso europeo de armonización en materia de derechos y libertades.

II. Participación de la jurisprudencia constitucional en el proceso de armonización europeo.

III. Categorización de los usos del TC del canon europeo.

IV. Consideraciones finales.

\section{PRESENTACIÓN}

La finalidad principal de estas páginas es mostrar de qué manera y con qué intensidad sigue el Tribunal Constitucional (TC) la jurisprudencia del Tribunal Europeo de Derechos Humanos (TEDH). Se parte de una concep-

$1 \mathrm{El}$ presente artículo se enmarca en un trabajo de investigación más amplio que supuso el objeto de la tesis doctoral "Los efectos interpretativos de las sentencias del tribunal europeo de derechos humanos. Especial consideración a la jurisprudencia del tribunal constitucional, dirigida por el Dr. E. Albertí Rovira y defendida en febrero de 2006 en la Facultad de Derecho de la Universidad de Barcelona. Aquella investigación, al igual que este trabajo, ha sido realizado en el marco del proyecto "El impacto del tratado constitucional europeo sobre la constitución interna" (SJE2005-08578), cuyo investigador principal es el Dr. E. Albertí. 
ción todavía hoy minoritaria entre la doctrina que defiende la obligatoriedad jurídica de los efectos interpretativos de las sentencias del Tribunal de Estrasburgo $^{2}$. En efecto, la naturaleza obligatoria de las sentencias de TEDH alcanza no sólo a sus efectos directos sino también a sus efectos indirectos o interpretativos que pueden identificarse con aquellos que superan el concepto de ejecución stricto sensu de las sentencias del TEDH. Esto efectos interpretativos son en gran parte responsables del proceso de armonización que lleva a cabo el TEDH a través de su jurisprudencia. Es un hecho incontestable que las sentencias del Tribunal de Estrasburgo, y más concretamente el desarrollo de los derechos y libertades convencionales y los criterios aplicados en la interpretación de aquellos, son utilizadas como canon, guía o instrumento interpretativo por las jurisdicciones internas en sus decisiones. Ahora bien, queda por averiguar cual es el uso real que hacen los jueces nacionales del canon europeo como herramienta hermenéutica. En esta línea se enmarcan las páginas que siguen donde pretende ofrecerse un análisis detallado de la utilización que nuestro Tribunal Constitucional ha hecho en los últimos años del Convenio Europeo de Derechos Humanos (CEDH) y, particularmente, de la jurisprudencia del TEDH como cánones interpretativos. Como eje de esta explicación se presenta una propuesta de categorización de los usos interpretativos que el TC ha dado al canon europeo que pretende facilitar la comprensión de cual es el alcance real de la incidencia del acquis conventionnel en el desarrollo del catálogo de derechos y libertades de nuestra Constitución y, mediatamente, de qué forma participa nuestro TC en el proceso de armonización del que, como se acaba de decir, son responsables en buena medida los efectos interpretativos de las SSTEDH.

\section{EL PROCESO EUROPEO DE ARMONIZACIÓN EN MATERIA DE DERECHOS Y LIBERTADES}

Gran parte de la doctrina admite hoy que la jurisprudencia del Tribunal Europeo de Derechos Humanos desempeña, además de una función de desarrollo del Convenio Europeo, una función armonizadora de los derechos fundamentales en el ámbito europeo ${ }^{3}$. Para comprender el alcance de la fun-

2 Esta afirmación debe ser, por supuesto, puesta en relación con toda una serie de argumentos y elementos relativos a la efectividad de la defendida obligatoriedad jurídica que, como se advertía en la nota anterior, no pueden ser expuestos en este momento.

3 Por ejemplo, M. DELMAS-MARTY, "Le rôle du juge européen dans la renaissance du jus commune- Signification et limites ", en P. MAHONEY, F. MATSCHER, H. PETZOLD, L. WILDHABER, Protection des droits de l'homme : la perspective européenne / Protecting Human Rights : the European perspective. Mélanges à la mémoire de/Studies in memory of Rolv Ryssdal, Colonia, 2000 , p. 412; igualmente, H. SCHERMERS, "A European Supreme Court", en P. MAHONEY, F. MATSCHER, H. PETZOLD, L. WILDHABER, Protection des droits de l'homme : la perspective européenne / Protecting Human Rights : the European perspective. Mélanges à la mémoire de/Studies in memory of Rolv Ryssdal, Colonia, 2000, p. 1273, o G. COHEN-JONATHAN, "La Convention eu- 
ción armonizadora de la jurisprudencia de Estrasburgo debe tenerse en cuenta, en primer lugar, que el $\mathrm{CEDH}$ ha pretendido erigirse en el estándar mínimo europeo en materia de derechos y libertades. Esto es así porque el $\mathrm{CEDH}$ es —al menos lo era en su origen — un texto de mínimos ${ }^{4}$, constituido por un catálogo limitado de derechos y libertades y, además, representa el nivel mínimo de garantía europeo, tal y como prescribe la cláusula de garantía mínima recogida en el art. $53 \mathrm{CEDH}$. En segundo lugar, el europeo es un sistema que asume la diversidad de los Estados que lo conforman. De hecho, el pluralismo es una de las bases sobre las que se asienta el CEDH ya que recoge en su propio redactado cláusulas que permiten que la diferencia sea una realidad ${ }^{5}$, que las distintas tradiciones jurídicas nacionales sean respetadas.

La consecuencia lógica de la existencia de tal estándar mínimo europeo y de la asunción del pluralismo sobre el que se asienta el CEDH supone aceptar que el sistema europeo de garantía implica un proceso de armonización en materia de derechos y libertades, y no de uniformización; de hecho, todavía hoy no puede afirmarse que exista un ius commune europeo de derechos y libertades ${ }^{6}$. En este contexto, el CEDH y la jurisprudencia del TEDH se erigen en un parámetro de mínimos y de reglas interpretativas de resolución de conflictos que todos los Estados parte deben respetar por ser, precisamente, el espacio que reconocen como común al ratificar el CEDH. En definitiva, a diferencia de la función uniformadora del Derecho comunitario que desempeña el Tribunal de Justicia de las Comunidades Europeas en el ámbito de la Unión Europea ${ }^{7}$, especialmente a través de la cuestión pre-

ropéenne des droits de l'homme et les systèmes nationaux des États contractants ", en Mélanges en l'honneur de Nicolas Valticos: Droit et justice, Paris, 1999, p. 392; por último, J. ANDRIANTSIMBAZOVINA, "La Cour Européenne des Droits de l'home à la croisée des chemins. Réflexions sur quelques tendances de la jurisprudence de la Cour européenne des droits de l'homme de 1999 à 2002 ", Cabiers de Droit Européen, 2002, núm. 5-6, p. 745.

4 En algunas cuestiones, como acertadamente señala V. FERRERES COMELLA, «El juez nacional ante los derechos fundamentales europeos. Algunas reflexiones en torno a la idea de diálogo", en A. SAIZ ARNAIZ (Dir.) y M. ZELAIA GARAGARZA (Coord.), Integración europea y poder judicial, Oñati, 2006, p. 236, el CEDH gracias al desarrollo que de él ha hecho el TEDH ha superado con creces aquellas previsiones minimalistas de alguno de los Estados fundadores del Consejo de Europa.

5 M. DELMAS-MARTY, "Pluralisme et traditions nationales", en P. TAVERNIER, (ed.): Quelle Europe pour les droits de l'homme? La Cour de Strasbourg et la réalisation d'une union plus étroite", Bruselas, 1996, p. 83.

6 A este respecto, véase, por ejemplo, M. DELMAS-MARTY, " Le rôle du juge européen... ", op. cit., p. 398. La inexistencia del ius commune se atribuye, por lo general, a la heterogeneidad todavía hoy persistente en el entorno europeo, tal y como han puesto de relieve, entre otros, M. DELMAS-MARTY, "Pluralisme et traditions nationales", op. cit., pp. 81-82, J. A. CARRILLO SALCEDO, J. A.: El Convenio europeo de derechos humanos, Madrid, 2003, p. 33. Íntimamente relacionado con la inexistencia de un ius commune europeo en materia de derechos fundamentales está la igualmente inexistente opinión pública europea, situación puesta de manifiesto recientemente por V. FERRERES COMELLA, “El juez nacional...”, op. cit., p. 239.

7 A este respecto V. FERRERES COMELLA, "El juez nacional..., op. cit., pp. 242-243, señala que la necesidad de "asegurar la uniforme aplicación del Derecho Comunitario" es una de las dos razones que justifican el carácter vinculante de la jurisprudencia del TJCE. 
judicial ${ }^{8}$, el TEDH a través de sus sentencias desempaña una función armonizadora de los sistemas de garantía existentes en Europa, incluido el propio sistema de protección de derechos y libertades fundamentales del ordenamiento comunitario.

Consecuencia del proceso de armonización es que la exigencia derivada del art. $1 \mathrm{CEDH}$ de conformidad de los ordenamientos jurídicos internos con el aquis conventionnel, constituido por el CEDH y la jurisprudencia del TEDH, deba entenderse en términos de compatibilidad ${ }^{9}$. La identidad podría exigirse, en su caso, respecto de un texto único e inmutable; sin embargo, la existencia del TEDH y la función de desarrollo que este realiza implica que el entendimiento de los derechos y libertades del CEDH, del estándar europeo, experimente cambios. La compatibilidad debe ser entendida en este contexto como principio de no contradicción de las medidas estatales con el estándar mínimo generado por el CEDH y la jurisprudencia del TEDH, tal y como se deduce del art. $53 \mathrm{CEDH}$. Asimismo, la compatibilidad, y no la identidad o la conformidad stricto sensu, hace efectivo el principio de subsidiariedad del sistema europeo y respeta el margen de apreciación unido a aquel principio porque se permite a los Estados parte elegir los medios para cumplir efectivamente con las obligaciones derivadas de la ratificación del CEDH sin que esto suponga menoscabar la efectividad del sistema; todo ello sin perjuicio de que el Tribunal de Estrasburgo tenga la última palabra sobre la potencial contradicción entre las medidas adoptadas por las autoridades nacionales y el estándar europeo. El parámetro de mínimos fijado desde Estrasburgo podrá ser siempre superado pero nunca rebajado por los Estados $^{10}$.

8 Para una completa explicación del papel de la cuestión prejudicial en su doble función como garante del mantenimiento de la uniformidad del Derecho comunitario y como vía indirecta de protección de los derechos fundamentales en el ámbito comunitario puede verse X. GÓMEZ SANZ y S. RIPOL CARULLA, "Cuestiones de política judicial y proceso europeo de integración jurídica", en A. SAIZ ARNAIZ (Dir.) y M. ZELAIA GARAGARZA (Coord.), Integración europea y poder judicial, Oñati, 2006, pp. 25 y ss.

9 Así lo ha entendido A. SAIZ ARNAIZ, La apertura constitucional..., op. cit., pp. 221-222, quien diferencia entre la conformidad como deducibilidad o identidad de contendido de la conformidad como compatibilidad o no contradicción en los contendido.

10 En este sentido debe señalarse que los tribunales internos en la resolución de un caso concreto podrán modificar el criterio establecido por Estrasburgo en casos análogos. En este caso el tribunal nacional debería hacer un especial esfuerzo por motivar esta separación del canon europeo, entre otras razones, porque de esta manera en el supuesto de que el asunto llegara finalmente a Estrasburgo se ofrecerían a este Tribunal los elementos argumentativos oportunos que podrían llevarle a no declarar vulnerado el $\mathrm{CEDH}$ e, incluso, a hacerle recapacitar sobre los criterios aplicados hasta el momento en asuntos similares al encausado. Se asegura así, además, el diálogo entre jurisdicciones necesario en el actual escenario europeo de concurrencia de sistemas de protección de los derechos y libertades fundamentales. Es cierto que la jurisprudencia del TEDH genera efecto de cosa interpretada con carácter vinculante pero esto no significa que los criterios y contenidos fijados por el Tribunal de Estrasburgo sean inamovibles. Como se ha explicado más arriba, el propio sistema de garantía asume y respeta la diversidad sobre la que se asienta.

Sobre estas cuestiones véase R. BUSTOS GISPERT, «La función jurisdiccional en escenario de pluralismo constitucional", en A. SAIZ ARNAIZ (Dir.) y M. ZELAIA GARAGARZA (Coord.), Inte- 
En este proceso de armonización es un elemento esencial el uso que las jurisdicciones internas hacen del canon europeo y muy especialmente de las sentencias del Tribunal Europeo como herramientas hermenéuticas. La utilización de la jurisprudencia del TEDH como instrumento interpretativo de sus propios catálogos internos de derechos y libertades se debe, en unos casos, a la existencia de una norma interna que prevea la necesidad de interpretación conforme con el estándar europeo. Este sería el caso de España donde el art. 10. 2 de la Constitución Española (CE) claramente establece la obligación de interpretación conforme y que supone el ejemplo paradigmático de este tipo de apertura al Derecho internacional. En otros casos, en cambio, se deberá al cumplimiento de la obligación general derivada del art. 1 CEDH de compatibilidad con el estándar europeo compuesto tanto por el CEDH como por la jurisprudencia del TEDH.

En cualquier caso, si bien es cierto que puede afirmarse que existe un seguimiento generalizado del canon europeo por las jurisdicciones internas, debe tenerse en cuenta que dicho seguimiento es desigual en su intensidad ${ }^{11}$. Precisamente es en nuestro ordenamiento jurídico y, concretamente, en la ju-

gración europea y poder judicial, Oñati, 2006, pp. 216-230, quien señala algunas de las consecuencias que producen los conflictos que se generan en este nuevo escenario de pluralismo en el que los distintos niveles jurisdiccionales están obligados a convivir.

11 Para valorar la efectividad real de la jurisprudencia del TEDH en los ordenamientos jurídicos deben valorarse tanto los condicionantes inherentes al sistema como los condicionantes propios de los distintos sistemas jurídicos de los Estados parte.

Los condicionantes inherentes al sistema son, por una parte, la continuidad y la previsibilidad, elementos que favorecerán el diálogo que existe entre Estrasburgo y las jurisdicciones nacionales en el proceso de armonización en los mínimos. Por otra parte, la jurisprudencia del TEDH debe caracterizarse por las notas de claridad y calidad, elementos que pueden verse dañados por el excesivo casuismo del TEDH en la resolución de demandas y por el afán de productividad de los jueces europeos, respectivamente. Siempre teniendo en cuenta que gran parte de responsabilidad en el diálogo Estrasburgo-Estados parte está en los jueces internos, el binomio claridad-calidad supone que las autoridades judiciales en la aplicación diaria de los derechos fundamentales, ya sea del CEDH o de sus propios catálogos de derechos, puedan conocer y entender cual es la doctrina que emana de Estrasburgo, haciendo innecesaria una reinterpretación de lo dicho por el TEDH.

En cuanto a los condicionantes inherentes a los distintos ordenamientos jurídicos debe senalarse, como punto de partida, que las autoridades internas hacen un seguimiento desigual de la jurisprudencia del TEDH. Varios han sido los elementos estudiados por la doctrina para justificar tal diversidad: la incorporación en el ordenamiento jurídico interno del $\mathrm{CEDH}$; la posición que ocupa el CEDH en el sistema de fuentes de los distintos Estados parte; la existencia de una declaración de derechos y su complitud; la consolidación de estos derechos en los sistemas internos que suele estar unido a la consolidación del propio sistema constitucional; la presencia más o menos explícita en las constituciones de cláusulas de apertura al Derecho internacional; por último, las opciones de política judicial de los órganos nacionales. Sin embargo, ninguna de estas condiciones es por sí sola determinante de la mayor o menor incidencia que la jurisprudencia de Estrasburgo ejerza en los distintos ordenamientos. El mayor o menor seguimiento que los jueces hagan de la jurisprudencia europea tendrá que ver, más bien, con la aplicación efectiva que los jueces hagan del CEDH y la relación que entable con las leyes internas, incluso con la existencia en el ordenamiento interno de un catálogo de derechos y de su contenido y, sobre todo, del grado de desarrollo que aquel disfrute. 
risprudencia del TC en donde se aprecia un nivel de compatibilización mayor respecto del canon europeo.

\title{
II. PARTICIPACIÓN DE LA JURISPRUDENCIA CONSTITUCIONAL EN EL PROCESO DE ARMONIZACIÓN EUROPEO
}

\author{
Se parte, pues, de que el TC hace un uso frecuente del CEDH y del TEDH
} como instrumentos interpretativos ${ }^{12} \mathrm{y}$ de que, en principio, tal uso se debe a la obligación de resultado impuesta por el art. 10. 2 CE. Ahora bien para conocer cual es la utilización real del canon europeo por parte del TC en su jurisprudencia relativa a derechos fundamentales debe llevarse a cabo un análisis en detalle y profundidad de sus sentencias. En las próximas páginas se ofrecen las conclusiones alcanzadas al respecto tras el análisis de las sentencias dictadas por el TC durante los años 1999 a 2004, etapa que puede reconocerse como de consolidación de la jurisprudencia constitucional ${ }^{13}$, y de en-

12 Merece la pena recordar ahora que en este trabajo no se aborda la compleja cuestión de la ejecución de las sentencias del TEDH en el ordenamiento jurídico español y, más concretamente, la postura adoptada por el TC sobre dicha cuestión. Señalaré ahora tan sólo que, como es sabido, en nuestro ordenamiento no existe ningún mecanismo legal de ejecución stricto sensu de las sentencias del Tribunal de Estrasburgo más haya del pago de la satisfacción equitativa en su caso establecida por el TEDH. Hasta hace poco tiempo parecía que podía afirmarse que el TC se reconocía competente, bajo unas condiciones muy específicas, para ejecutar las sentencias del TEDH en tanto que el legislador no previera una vía concreta para ello (así lo había defendido en el trabajo A. QUERALT JIMÉNEZ, El Tribunal de Estrasburgo: una jurisdicción internacional para la protección de los derechos fundamentales, Valencia, 2003, pp. pp. 227-229, en nota a pie). Sin embargo, en las SSTC 313/2005 y 197/2006 el Tribunal Constitucional hace una aplicación tan sumamente restrictiva, y un tanto forzada a mi modo de ver, de los criterios sentados en la STC 245/1991, sobre todo en lo relativo al concepto de lesión actual del derecho, que parecería que el TC, sin reconocerlo expresamente, renuncia a la posibilidad de ejecutar las decisiones de Estrasburgo, sean cuales sean las circunstancias del caso. Además, la posición mantenida hasta ahora por el TC respecto de la posibilidad de utilizar el procedimiento de revisión penal como mecanismo de ejecución de las SSTEDH en tanto no haya una vía legalmente prevista a tal fin parece haber sido modificada en la STC 240/2005 en la que parece que sólo se prevé que pueda considerarse como "hecho nuevo" (art. 954. 4 LECrim) una STEDH dictada en un procedimiento distinto. Esta parece ser también la percepción del Magistrado P. PÉREZ TREMPS tal y como se desprende de su Voto Particular concurrente a la STC 197/2006, con la salvedad hecha de que considera que la nueva posición del TC no debe entenderse como "doctrina" en tanto que se encuentra recogida como obiter dictum. En cualquier caso, lo que sí es cierto es que estas últimas sentencias no aclaran, más bien al contrario, cual es la respuesta que deben esperar los recurrentes en amparo que intenten que se ejecute una sentencia de Estrasburgo dictada a su favor.

13 La categorización que aquí se propone fue construida en su momento sobre el análisis empírico de las sentencias del TC dictadas entre los años 1999-2004; con el objeto de no desnaturalizar las conclusiones alcanzadas se ha optado en este momento por no entrar a examinar de forma pormenorizada las sentencias dictadas en los años 2005 y 2006. En cualquier caso, un estudio aproximativo a estas últimas decisiones permite afirmar que la actividad del TC en estos dos últimos años sigue las pautas marcadas en la categorización propuesta. De hecho, en las próximas páginas se incluyen datos sobre la jurisprudencia más reciente del TC que así lo pone de manifiesto. 
tre las que puede destacarse una propuesta de categorización de los usos que el TC realiza del canon europeo. Como se ha anunciado en la presentación de este trabajo, esta categorización pretende, además de poner de manifiesto el seguimiento real que nuestra jurisdicción constitucional hace del canon europeo en el desarrollo de los derechos y libertades reconocidos en la Constitución, mostrar de qué manera participa en el proceso europeo de armonización en materia de derechos fundamentales ${ }^{14}$.

\section{AlgunAs REFERENCIAS NUMÉRICAS}

Cuantitativamente el estudio de la jurisprudencia constitucional revela que el TC hace referencia expresa a los instrumentos de interpretación europeos casi en un 19\% de las sentencias dictadas entre los años 1999-2004, y en casi un 21\% de las sentencias dictadas en amparo. Esta cifra supone un aumento notable respecto de la etapa anterior, si se tiene en cuenta que entre los años 1981 y 1997 sólo en el 10\% de las sentencias dictadas por el TC se

14 En la realización de esta categorización han resultado imprescindibles los datos aportados y las conclusiones alcanzadas por otros autores en trabajos previos, véase, E. GARCÍA DE ENTERRÍA, (coord.), E. LINDE, L. I. ORTEGA, M. SÁNCHEZ MORÓN, Eficacia de la Convención en el Derecho Español, en El sistema europeo de protección de los derechos humanos. Estudio de la Convención y de la Jurisprudencia del Tribunal Europeo de Derechos Humanos, Madrid, 1983; D. LIÑÁN NOGUERAS, "Efectos de las STEDH...”, op. cit., pp. 355 y ss.; C. FERNÁNDEZ CASADEVANTE, La aplicación del Convenio Europeo de Derechos Humanos en España, Madrid, 1988; J. DELGADO BARRIO, «Proyección de las decisiones del Tribunal Europeo de Derechos Humanos en la Jurisprudencia española", $R A P, 1989$, núm. 119; E. GARCÍA DE ENTERRÍA, "El valor en Derecho español de la jurisprudencia del Tribunal Europeo de Derechos Humanos", BICAM, núm. 1, 1987; M. A. APARICIO PÉREZ, "La cláusula interpretativa del artículo 10. 2 de la Constitución española, como cláusula de integración y apertura constitucional de los derechos fundamentales", Revista jueces para la Democracia, núm. 6, 1989, pp. 7 y ss.; F. REY MARTíNEZ, "El criterio interpretativo de los derechos fundamentales conforme a las normas internacionales (Análisis del art. 10. 2 CE)", Revista General de Derecho, núm. 537, 1989; E. GARCÍA DE ENTERRÍA, "Valeur de la jurisprudence de la Cour européenne des droits de l'Homme en droit espagnol", en F. MATSCHER, y H. PETZOLD (eds.): Protecting human rights: the European dimension: studies in honour of Gérard J. Wiarda. Protection des droits de l'homme: la dimension européenne: mélanges en l'honneur de Gérard J. Wiarda, Colonia, 2. ${ }^{a}$ ed, 1990; A. CARRILLO SALCEDO, "España y la protección de los derechos humanos: el papel del Tribunal Europeo de Derechos Humanos y del Tribunal Constitucional españon, en $A V$, Vol. 32, núm. 2, 1994; L. MARTíN-RETORTILLO, "La recepción por el Tribunal Constitucional de la Jurisprudencai del Tribunal Europeo de Derechos Humanos", en La Europa de los Derechos Humanos, Madrid, 1998; VVAA, Informe realizado por la Delegación española del Tribunal Constitucional sobre "Protection constitutionnelle et protection des droits de l'homme: concurrence ou complémntarieté?", en IX Conférence des cours constitutionnelles européennes, París, 1993, pp. 267-312; J. M. CASTELLÀ ANDREU, «El art. 10. 2 de la Constitución como canon de interpretación de los Derechos Fundamentales", en M. A. APARICIO PÉREZ (coord.), Derechos constitucionales y formas políticas. Actas del Congreso sobre derechos constitucionales y Estado Autonómico, Barcelona, 2001, pp. 141-164; especial referencia debe realizarse a A. SAIZ ARNAIZ, La apertura constitucional al derecho internacional europeo de los derechos humanos. El art. 10. 2 de la CE, Madrid, 1999. 
hacía mención expresa de fuentes internacionales (no sólo del CEDH y del TEDH) y concretamente un 13\% de los recursos de amparo.

Desde una perspectiva cualitativa el análisis de las sentencias estudiadas pone de relieve, entre otros, la notable incidencia del canon europeo en las sentencias de Pleno en las que se resolvía un recurso de amparo. En 25 de las 34 sentencias en amparo dictadas por el Pleno entre 1999 y 2004 se utilizan los instrumentos ofrecidos por el sistema europeo de garantía como herramientas interpretativas de los derechos fundamentales afectados; lo que supone un $73,52 \%$ de los casos, esto es, en 3 de cada 4 SSTC. ${ }^{15}$ Este dato cuantitativo respecto de las sentencias de Pleno adquiere especial relevancia porque, como es sabido, es precisamente en este tipo de decisiones en las que suelen tratarse los temas más delicados y son también las sentencias de Pleno las encargadas de introducir los cambios de criterio en la jurisprudencia del Tribunal.

Los siguientes cuadros pueden ayudar a entender la incidencia cuantitativa de las referencias a los instrumentos europeos en las sentencias del TC (1999-2004):

\begin{tabular}{|c|c|c|c|}
\hline & $\begin{array}{c}\text { SSTC } \\
\text { dictadas }\end{array}$ & $\begin{array}{l}\text { SSTC con } \\
\text { ref. europeas }\end{array}$ & \\
\hline 1999 & 242 & 38 & \\
\hline 2000 & 312 & 57 & \\
\hline 2001 & 240 & 48 & \\
\hline 2002 & 239 & 60 & \\
\hline 2003 & 230 & 39 & \\
\hline 2004 & 255 & 49 & \\
\hline TOTAL & 1.518 & 292 & $19,24 \%$ \\
\hline
\end{tabular}

\begin{tabular}{|c|c|c|c|c|}
\hline & $\begin{array}{c}\text { SSTC } \\
\text { en } \text { amparo }^{16}\end{array}$ & $\begin{array}{l}\text { SSTC en amparo } \\
\text { con ref. europeas }\end{array}$ & & 10.2 CE \\
\hline 1999 & 221 & 36 & & 10 \\
\hline 2000 & 280 & 52 & & 11 \\
\hline 2001 & 222 & 47 & & 9 \\
\hline 2002 & 223 & 656 & & 12 \\
\hline 2003 & 207 & 36 & & 9 \\
\hline 2004 & 195 & 47 & & 10 \\
\hline TOTAL & 1.348 & 274 & $20,33 \%$ & 61 \\
\hline
\end{tabular}

15 En 2005 fueron avocados tres recursos de amparo al Pleno del TC: en dos ellos se incluyen referencias al canon europeo (STC 123/2005 y STC 292/2005). En 2006, en cambio, en ninguno de los tres recursos de amparo resueltos por el Pleno del TC aparece el uso del canon europeo como instrumento interpretativos; aparecen en cambio referencias al Derechos Comunitario y a decisiones del Tribunal de Justicia de las Comunidades Europeas en la STC 16/2006.

16 Incluidas las sentencias dictadas por el Pleno. 


\begin{tabular}{|c|c|c|c|c|}
\hline & $\begin{array}{l}\text { SSTC } \\
\text { en R.I. }\end{array}$ & $\begin{array}{l}\text { SSTC con } \\
\text { ref. europeas }\end{array}$ & & 10.2 CE \\
\hline 1999 & 10 & 1 & & 0 \\
\hline 2000 & 16 & 2 & & 0 \\
\hline 2001 & 6 & 0 & & 0 \\
\hline 2002 & 10 & 2 & & 1 \\
\hline 2003 & 11 & 3 & & 1 \\
\hline 2004 & 11 & 0 & & 0 \\
\hline TOTAL & 64 & 8 & $12,50 \%$ & 2 \\
\hline
\end{tabular}

\begin{tabular}{|c|c|c|c|c|}
\hline & $\begin{array}{c}\text { SSTC } \\
\text { en C.I. }\end{array}$ & $\begin{array}{l}\text { SSTC en amparo } \\
\text { con ref. europeas }\end{array}$ & & $10.2 \mathrm{CE}$ \\
\hline 1999 & 6 & 1 & & 0 \\
\hline 2000 & 35 & 3 & & 1 \\
\hline 2001 & 6 & 1 & & 0 \\
\hline 2002 & 5 & 2 & & 0 \\
\hline 2003 & 8 & 1 & & 0 \\
\hline 2004 & 46 & 2 & & 0 \\
\hline TOTAL & 106 & 10 & $9,43 \%$ & 1 \\
\hline
\end{tabular}

\begin{tabular}{|c|c|c|c|c|}
\hline & $\begin{array}{c}\text { SSTC de Pleno } \\
\text { en recurso } \\
\text { de amparo }\end{array}$ & $\begin{array}{l}\text { SSTC en amparo } \\
\text { con ref. europeas }\end{array}$ & \multirow[b]{8}{*}{$73,52 \%$} & $10.2 \mathrm{CE}$ \\
\hline 1999 & 2 & 2 & & 2 \\
\hline 2000 & 5 & 2 & & 0 \\
\hline 2001 & 14 & 12 & & 5 \\
\hline 2002 & 6 & 5 & & 0 \\
\hline 2003 & 5 & 2 & & 2 \\
\hline 2004 & 2 & 2 & & 1 \\
\hline TOTAL & 34 & 25 & & 0 \\
\hline
\end{tabular}

2. VirTUALIDAd PRÁCTICA DEL ART. 10. 2 CE

Al hilo del estudio de las sentencias seleccionadas se han obtenido igualmente relevantes resultados respecto de la virtualidad práctica del art. 10. 2 $\mathrm{CE}$, dicho de otro modo, respecto de cual es su utilización e incidencia en la relación que se establece entre el canon europeo y el canon constitucional. 
En primer lugar, el estudio empírico confirma la indudable naturaleza obligatoria de dicho precepto en el que efectivamente se recoge un mandato dirigido a los aplicadores del Derecho que impone la utilización del estándar internacional como instrumento interpretativo en materia de derechos fundamentales. Este mandato, sin embargo, no puede ser entendido en ningún caso como un instrumento a través del que el canon europeo pueda convertirse en parámetro autónomo de control constitucional ${ }^{17}$.

Dicho lo anterior, y partiendo de que el art. 10. 2 CE contiene un mandato de interpretación conforme, el valor interpretativo del CEDH y de la jurisprudencia del TEDH es el mismo tanto si su utilización viene precedida del art. 10. 2 CE como si no lo hace. Tanto es así que en muchas ocasiones, la referencia explícita de la cláusula de apertura internacional queda en una mera formalidad y aparece como un recordatorio esporádico del mandato de interpretación conforme o, en algunos casos, como una forma de justificación de la utilización de los instrumentos europeos. En ningún caso la mención expresa del art. 10. 2 CE varía la intensidad con la que el TC utiliza el canon interpretativo europeo. De hecho, la referencia explícita del art. 10. 2 CE sólo se produce en un $22 \%$ de los casos, lo que indica la escasa entidad material que en sí misma posee la cita del art. 10. 2 CE. Con esto quiere decirse que la significación y relevancia de esta cláusula de apertura no está en si es más o menos aludida por los aplicadores del Derechos sino en su propia incorporación en la CE y en la utilización generalizada por parte del TC de los tratados internacionales como instrumentos interpretativos en materia de derechos fundamentales, lo que supone el cumplimiento de su mandato.

Ahora bien, debe advertirse en relación con el proceso de armonización antes presentado que el Tribunal Constitucional además de utilizar como instrumento interpretativo el canon europeo ratificado en virtud de la obligación prescrita en el art. 10. 2 CE, utiliza igualmente el canon europeo no ratificado por España aplicación que desborda el alcance del art. 10. 2 CE. Esta actitud del TC responde más bien a la consideración del estándar europeo en su conjunto, lo que implica tener en cuenta tanto el CEDH y los Protocolos ratificados por España como los Protocolos no ratificados (todavía) por nuestro Estado. El Tribunal Constitucional actúa de esta forma porque, como se mostrará con ejemplos concretos más abajo, reconoce aquellos textos como parte integrante del estándar común europeo que el TEDH se encarga de desarrollar. Este fenómeno puede tomarse como prueba clara de que la virtualidad interpretativa de las sentencias del TEDH supera la cuestión relativa a la posición del CEDH y de los Protocolos adicionales en los ordenamientos jurídicos de los Estados parte y a las cláusulas de apertura internacional que aquellos pudieran contener. Es cierto que el establecimiento de cláusulas de

17 Diferente sería que fuera interpuesto ante el TC un recurso de amparo por la vulneración de un derecho de la sección $1 .^{a}$ del capítulo 2. ${ }^{a}$ del Título I con el alcance resultante de su interpretación conforme, en virtud del art. 10. 2 CE, con el CEDH y la jurisprudencia del TEDH. 
apertura internacional facilitará la utilización de los textos europeos como instrumentos interpretativos por parte de las jurisdicciones nacionales, como demuestra claramente el caso español. Sin embargo, dicho elemento no puede considerarse como determinante. Lo cierto es que la compatibilización entre cánones responde, no siempre conscientemente, al reconocimiento de la obligación general derivada del CEDH de interpretación conforme el acquis conventionnel y de la posición del TEDH como intérprete supremo del canon europeo. El efecto de cosa interpretada que deriva de las sentencias del TEDH alcanza así tanto a los intérpretes internos del CEDH como a los aplicadores de los catálogos constitucionales de derechos fundamentales.

\section{Causas para el uso del Canon europeo}

En numerosas ocasiones ha sido puesto de manifiesto por la doctrina que más allá del cumplimiento del mandato que contiene el art. 10. 2 CE no se conocen las causas concretas que en cada caso lleva a una Sala o al Pleno del TC a apoyar de manera más o menos intensa sus argumentaciones jurídicas en los instrumentos europeos ${ }^{18}$; no existe, en palabras de Saiz Arnaiz, una formulación teórica que de respuesta a este fenómeno ${ }^{19}$. El análisis empírico de las sentencias del TC permite, eso sí, intuir cuales son las principales causas, no siempre explicitadas, que suelen llevar al TC a utilizar el canon europeo como instrumento interpretativo. Parece claro, de entrada, que subyace a todas las sentencias la voluntad del Tribunal de mostrar la sintonía generalizada de su doctrina con el estándar europeo que representan el CEDH y la jurisprudencia del TEDH; en definitiva, el TC busca poner de manifiesto la compatibilidad entre el nivel de garantía reconocido por nuestro sistema de derechos fundamentales y el acquis conventionnel. Así se deduce del uso mayoritario que el TC hace de las referencias a los instrumentos europeos cuya función se limita a mostrar el acuerdo existente entre su jurisprudencia, la ya consolidada, y el desarrollo que el Tribunal de Estrasburgo hace del Convenio. La intención última de esta actitud sea quizá evitar una sentencia contra España declarativa de la violación del CEDH tras la interposición de una demanda ante el sistema de garantía europeo por un recurrente en amparo dis-

18 A este respecto L. MARTÍN-RETORTILLO BAQUER, "La recepción por el Tribunal Constitucional de la jurisprudencia del TEDH", RAP, núm. 137, 1995, pp. 12 y 13, señalaba que la fascinación que demostró el TC por la jurisprudencia del TEDH en sus primeros años de actividad se debía fundamentalmente a que el CEDH aparecía como un sistema completo, esto es, un catálogo de derechos acompañado de un mecanismo de garantía de estos derechos que los interpretaba y desarrollaba; segundo, el TEDH aparecía en el escenario europeo como una instancia, que si bien no era permanente, estaba conformada por juristas de reconocido prestigio profesional en sus países de origen y contaba con 30 años de experiencia jurisdiccional. Tenían muy pocos casos y, por tanto, las SSTEDH se caracterizaban por ser de mucha calidad, claras y muy trabajadas.

19 A. SAIZ ARNAIZ, La apertura constitucional..., op. cit., p. 167. 
conforme con la solución adoptada por el TC para su asunto. Recuérdese que el TEDH tiene la última palabra sobre la compatibilidad con el CEDH de las medidas adoptadas por las autoridades estatales.

Ahora bien, además de esta voluntad de sintonía con el canon europeo, de las sentencias constitucionales se destilan otras causas concretas que parecen inspirar el uso de las referencias europeas por parte del intérprete supremo de la Constitución.

En primer lugar, puede mencionarse la complejidad de un determinado asunto, complejidad generalmente asociada a los hechos de los que aquel trae causa. En estos supuestos el TC debe identificar los distintos elementos en juego y para ello es de gran utilidad contar con un referente europeo que le ofrece los criterios aplicados en casos similares. La situación descrita se produce a menudo en asuntos relativos a una colisión entre los derechos del art. 18. 1 CE y las libertades del art. 20. $1 \mathrm{CE}^{20}$. El uso del canon europeo aparece, igualmente, ante la falta de precedente claro en la jurisprudencia constitucional lo que provoca que el Tribunal se apoye en el referente que le proporciona el canon de Estrasburgo para encontrar soluciones a situaciones análogas ${ }^{21}$. También se explicita el uso del canon europeo por la mayor persuasividad que ofrece a los argumentos esgrimidos y, a la postre, a la decisión finalmente adoptada por el TC; la mayor persuasividad que parecen ofrecer las referencias al CEDH o a la jurisprudencia del TEDH suele aprovecharse en asuntos especialmente sensibles por la expectación o repercusiones jurídicas, sociales e incluso políticas que puede provocar el fallo de la sentencia constitucional ${ }^{22}$, incluidas en este apartado determinadas restricciones a los derechos y libertades ${ }^{23}$. Asimismo, es abundante la referencia al CEDH y a la jurisprudencia europea en aquellos supuestos en los que es necesario dotar de contenido aprehensible a distintos conceptos jurídicos abiertos que se encuentran en la delimitación de alguno de los derechos fundamentales reconocidos en la Constitución.

Por último, y sin ánimo de exhaustividad, otra de las causas que parecen originar la alusión a los instrumentos europeos como herramientas interpretativas es, precisamente, la necesidad de compatibilizar la doctrina del TC con el estándar europeo que, en ocasiones, evoluciona antes que el estándar constitucional, al menos el estándar reconocido por el Tribunal Constitucional ${ }^{24}$. En estos casos, la compatibilización supone descubrir una facultad, garantía o posición jurídica de un derecho fundamental hasta entonces no explicitada por la jurisprudencia constitucional.

20 Por todas, STC $76 / 2002$, F. J. 2.

21 Un caso claro es la STC 48/2003, sentencia que resolvía el recurso de inconstitucionalidad promovido por el Gobierno Vasco contra diferentes artículos de la LO 6/2002, de 27 de junio, de Partidos Políticos.

22 Por ejemplo, STC 36/1999 y STC 155/2002

23 STC 154/2002, respecto de los testigos de Jehová.

24 Vid. A. QUERALT JIMÉNEZ, "The access to justice in Spain", en The protection of Human Rights in Europe: National and European Judge, ERPL/REDP, vol. 13, no. 2, summer/été, 2001, p. 623. 
En cualquier caso debe tenerse en cuenta que las causas que acaban de sugerirse como la razón que lleva la TC a usar el canon europeo pueden, en ocasiones, concurrir en una misma sentencia ${ }^{25}$, sin que pueda determinarse en la mayoría de los casos si es una de ellas o varias conjuntamente las que llevaron al TC a explicitar el uso de las referencias a los instrumentos europeos. Sólo en el último de los supuestos expuestos, la compatibilización del estándar constitucional con el europeo, el TC identifica en ocasiones tal finalidad como la causa que motivó el uso del canon europeo ${ }^{26}$.

\section{CATEGORIZACIÓN DE LOS USOS DEL TC DEL CANON EUROPEO}

\section{CONSIDERACIONES PREVIAS}

Antes de entrar en la exposición de la categorización que aquí se propone deben realizarse una serie de advertencias que favorecerán una ajustada comprensión de la intensidad real de la influencia del canon europeo en la jurisprudencia del TC en materia de derechos fundamentales. En primer lugar, únicamente son susceptibles de estudio las referencias explícitas al canon europeo y no aquellas que por encontrarse ya integradas en el parámetro constitucional pueden entenderse presentes únicamente de forma implícita. En segundo lugar, debe señalarse que la aparente forma con la que venga presentada la referencia al o a los instrumentos interpretativos europeos no determina, tampoco, el uso que de ellos vaya a hacerse; en otras palabras, lo aparentemente intenso o abundante de una cita no condiciona la incidencia real de la utilización del canon europeo como instrumento interpretativo en la jurisprudencia del $\mathrm{TC}^{27}$. En efecto, la realidad es que en la mayoría de sentencias estudiadas el Tribunal se limita a reiterar los argumentos jurídicos ya consolidados en su doctrina y con ellos las referencias europeas que han quedado integradas en el parámetro constitucional o, simplemente, en el esteriotipo de argumento jurídico que el TC aplica en ocasiones de manera mecánica. Esta situación se agrava ya que, en ocasiones, el Tribunal cita la jurisprudencia del TEDH sin reparar en los matices que cada decisión pueda presentar. Se produce, igualmente, una cierta tendencia a la actualización constante de las referencias jurisprudenciales europeas que, respondiendo a

25 Por ejemplo, puede ocurrir que la persuasividad se presente conjuntamente con la ausencia de precedentes constitucionales claros en asuntos especialmente sensibles; por ejemplo, la ya citada STC 48/2003.

26 Cabe apuntar, igualmente, que por lo general el TC no se siente vinculado por las referencias a los instrumentos europeos que las partes del proceso, públicas y particulares, aporten en sus alegaciones.

27 Véase, por ejemplo, STC 19/1999, F. J. 5. 
aquella actitud poco delicada, no siempre se corresponden con exactitud con los hechos estudiados en el amparo.

\section{Propuesta de CATEgorización de los usos interpretativos DEL CANON EUROPEO}

La categorización propuesta distingue entre usos que el TC hace del canon europeo como instrumento interpretativo y formas en las que aquellos usos se manifiestan. Entre los usos que se proponen como ejes de la categorización se da una relación de gradación en su intensidad. Los usos sobre los que se construye la propuesta de categorización son los siguientes: el canon europeo como argumento de autoridad ad abundantiam, el canon europeo como argumento de autoridad complementario, la incorporación de pautas interpretativas y la incorporación de contenidos; por último, la muestra del desarrollo incipiente del ius commune europeo en materia de derechos y libertades.

\subsection{El argumento de autoridad}

El uso más corriente y abundante de las referencias a los instrumentos europeos, ya sea al CEDH y/o a la jurisprudencia del TEDH, es el argumento de autoridad: en estos casos la cita de los instrumentos europeos, más o menos detallada, tiene como finalidad esencial mostrar la conformidad del estándar constitucional con el estándar europeo, siempre entendiendo conformidad como compatibilidad. Dentro de este uso de los instrumentos europeos como herramientas interpretativas puede hacerse una gradación que va desde la cita del CEDH y/o de la jurisprudencia del TEDH como mero argumento de autoridad ad abundantiam, que se suma a los argumentos propiamente constitucionales y que no aporta materialmente nada a los motivos jurídicos ofrecidos por el TC respecto de una determinada cuestión, hasta un argumento de autoridad complementario que no incorpora nuevos contenidos a la jurisprudencia del TC pero, además de mostrar la conformidad con el estándar fijado en Estrasburgo, refuerza especialmente la argumentación o razonamiento elaborados por el TC; en este último caso, las referencias a los instrumentos europeos cuentan con un valor añadido propio como se mostrará en breve.

Prácticamente todos los derechos fundamentales de la Sección 1. ${ }^{a}$ del Capítulo 2. ${ }^{\circ}$ del Título I de la CE se han visto afectados por el uso del canon europeo como argumento de autoridad. Puede destacarse el uso del CEDH y la jurisprudencia del TEDH respecto de los derechos y libertades reconocidos en los arts. 18 y $20 \mathrm{CE}$ y, especialmente, respecto de los conflictos entre ellos. Seguramente, la razón por la que el TC utiliza frecuentemente en estos casos el canon europeo como herramienta interpretativa está en la variedad de soluciones que pueden ofrecerse según sean los hechos concurrentes. Asimismo, el estudio revela que las referencias a los instrumentos europeos tanto como 
argumento de autoridad ad abundantiam como complementario son frecuentes en relación con las garantías aplicables en el orden penal, esencialmente las recogidas en los arts. 17 y 24 CE.

\section{A. Argumento de autoridad ad abundantiam}

Dentro de la primera categoría, el argumento de autoridad ad abundantiam, aparecen diferentes formas de cita o referencia a las herramientas ofrecidas por el sistema europeo de garantía de los derechos fundamentales; todas son redundantes; su supresión no supondría una pérdida materialmente relevante en la argumentación jurídica del TC. Esta circunstancia se produce sobre todo en relación con derechos fundamentales respecto de los que existe una jurisprudencia constitucional consolidada y respecto de los que la verdadera adecuación a Estrasburgo o incorporación desde Estrasburgo se produjo en la primera jurisprudencia constitucional. En la actualidad la cita de los referentes europeos puede considerarse más bien como una cláusula de estilo. En efecto, una aproximación primera y superficial a las sentencias constitucionales ofrece una muy positiva opinión de la actitud del TC respecto del canon europeo ya que aquel sigue explicitando con notable frecuencia la influencia del estándar europeo en sus decisiones pese a que, tras casi 25 años de funcionamiento, cuenta ya con una consolidada jurisprudencia respecto de la gran mayoría de derechos fundamentales. Sin embargo, un estudio algo más detenido de la jurisprudencia constitucional de los últimos años permite apreciar que el TC hace un uso un tanto mecánico de la jurisprudencia del TEDH, coincidiendo con un uso igualmente mecánico de la propia jurisprudencia constitucional. Esta circunstancia, por otra parte, no es extraña a los órganos jurisdiccionales, nacionales o internacionales, que, en general, con el paso del tiempo adoptan ciertas fórmulas argumentativas que aplican sucesivamente para dar respuesta a cuestiones que se repiten ante ellos una y otra vez. En cualquier caso, en relación con el canon europeo, la situación descrita provoca que aquel pierda la intensidad con la que en su momento incidió en la jurisprudencia constitucional y pase a ser, como se dijo unas líneas más arriba, un argumento ad abundantiam.

En cuanto a las formas en las que aparece este uso, la más común es la manifestación de la sintonía entre estándar europeo y constitucional que pretende demostrar a través de determinadas fórmulas y expresiones la coincidencia del criterio constitucionalmente adoptado con el existente en el sistema europeo, unas veces con CEDH y, en la mayoría de casos, respecto de la jurisprudencia del $\mathrm{TEDH}^{28}$. Normalmente se acompaña de la cita de sen-

28 Entre muchos otros, por ejemplo, "en el mismo sentido..." (STC 14/1999), "criterio este que también fue uno de los que tuvo en mente el TEDH..." (STC 276/2000), "de conformidad con..." (STC 38/2002). 
tencias dictadas por el Tribunal Europeo, aunque en ocasiones la referencia al sistema europeo es más general y se cita únicamente el CEDH o se hace una referencia genérica a la jurisprudencia del TEDH. En ocasiones la muestra de sintonía con el sistema europeo de garantía se produce mediante la trascripción de una STC anterior, que debilita si cabe todavía más la intensidad del uso del referente europeo. Otra forma es la cita sucesiva de decisiones constitucionales y europeas, fórmula ampliamente extendida en la jurisprudencia constitucional que consiste en citar a modo de apoyo al argumento esgrimido, una o varias sentencias del TC y continuación una o varias sentencias del $\mathrm{TEDH}^{29}$. Por lo general, a diferencia de lo que ocurre en otros casos, el TC no acompaña la cita de las decisiones europeas de ninguna cláusula que explique o adelante el uso de dichas decisiones como instrumento interpretativo, sino que simplemente las incorpora en el texto. En otras ocasiones, el TC manifiesta la conformidad del sistema constitucional de garantía con el estándar europeo mediante la cita, y en ocasiones la trascripción, de alguno de los preceptos del CEDH - también del PIDCP y, en menor medida de la DUDHprescindiendo de referencias a la jurisprudencia del TEDH o de la cita de alguna de sus sentencias ${ }^{30}$. Si bien es cierto que en la primera etapa de desarrollo de la jurisprudencia constitucional la cita del CEDH podía suponer la incorporación de nuevas facultades o elementos no expresamente previstos por el sistema constitucional de derechos fundamentales, en la actual etapa de consolidación constitucional la utilización de los textos internacionales se ha convertido en una mera cláusula de estilo. En ocasiones la manifestación del argumento interpretativo ad abundantiam aparece con la cita autónoma del CEDH o de una STEDH lo que responde, por lo general, a una elección aleatoria del ponente. Esta forma podría hacer pensar que la referencia europea funciona como parámetro interpretativo único, sustituyendo o colaborando, en su caso, con el parámetro constitucional ${ }^{31}$. Sin embargo, la realidad demuestra que se trata, más bien, de licencias estilísticas en las que la cita del Convenio o de la jurisprudencia del TEDH se limita a reiterar una estructura ya repetida o una doctrina constitucional plenamente asumida. Por último, el argumento ad abundantiam aparece en otras ocasiones en forma de remisión a sentencias dictadas por el TC con anterioridad en las que aparecían referencias al CEDH o a la jurisprudencia de Estrasburgo. Este es, sin duda, uno de los supuestos en los que la sintonía general de la jurisprudencia del TC con el estándar europeo se hace más patente puesto que en muchas ocasiones el TC a través de la remisión admite, no siempre expresamente, "haber becho suya" en un momento anterior la jurisprudencia del TEDH respecto de un determinado aspecto relativo a un derecho fundamental ${ }^{32}$.

29 Entre muchos otros, por ejemplo, 74/1999, 134/1999, 192/1999, 187/1999, 102/2000, $179 / 2000,212 / 2000$.

30 Entre muchos otros, por ejemplo, STC 32/1999, F. J. 3, STC 124/2000, F. J. 5; como ejemplo más reciente, STC 292/2005 (Pleno), F. J. 3.

31 Entre muchos otros, por ejemplo, STC 127/2000, F. J. 3, STC 11/2000, F. J. 4.

32 Por ejemplo, STC 174/2001, F. J. 3. 


\section{B. Argumento de autoridad complementario}

A diferencia del argumento ad abundantiam, el complementario destaca porque, pese a no suponer la incorporación de nuevos elementos en la configuración de los derechos fundamentales, su utilización sí implica un valor interpretativo relevante en el sentido de que refuerza efectivamente una determinada argumentación vertida por el TC, corroborando su propia posición. Incluso formalmente el argumento complementario se caracteriza por un estilo más depurado por parte del TC que hace un esfuerzo por escoger los elementos más destacables del canon europeo para plasmarlos en sus sentencias. Así, el TC suele escapar de las estructuras argumentativas sucesivamente repetidas en decisiones anteriores, incluidas en ellas las referencias a los instrumentos europeos, e intenta buscar los referentes que más se ajusten a sus necesidades, afinando algo más en la elección de las decisiones europeas. Por lo general no se recurre a la lista de decisiones ya elaboradas y asociadas por grupos a los distintos elementos que configuran los derechos fundamentales sino que son escogidas de forma novedosa. En algunos casos podría afirmarse, incluso, que el TC realiza no sólo un test de constitucionalidad de las medidas adoptadas por los poderes públicos que supuestamente lesionan los derechos fundamentales, sino que, además, lleva a cabo un test de convencionalidad. Esto es así porque el argumento de autoridad complementario se mueve en un terreno que va desde la corroboración de la posición adoptada por el TC hasta la aplicación, como mínimo aparentemente, de una doble test de validez compuesto por la aplicación del test de constitucionalidad y, posteriormente, por la comprobación de que la medida analizada también supera el test de convencionalidad.

La utilización del argumento de autoridad complementario por parte del TC suele venir justificada por las causas exógenas que se señalaron más arriba. La concurrencia de estas causas provoca que el Tribunal deba hacer un esfuerzo argumentativo y justificativo superior al que realiza cuando resuelve asuntos respecto de los que existe jurisprudencia constitucional ampliamente consolidada y que no presentan especial complicación ni fáctica ni jurídica.

La exteriorización de este uso se produce, igualmente, a través de distintas formas. En primer lugar, se observa la realización de un test de conformidad mediante el que el TC muestra la coincidencia de sus criterios con los aplicados en Estrasburgo ${ }^{33}$. En estos casos el TC hace un esfuerzo por señalar la sintonía de sus puntos de partida con el CEDH y los criterios concretamente aplicados con la jurisprudencia del TEDH eligiendo, asimismo, aquellas sentencias que pudieran parecer más pertinentes a los argumentos defendidos. Otra forma de exteriorización es la de utilizar las sentencias del TEDH como precedente para asuntos de complejidad fáctica ${ }^{34}$. Se trata de supuestos en los

33 Por ejemplo, STC 219/2001, F. J. 7.

34 Por ejemplo, STC 204/2001, F. J. 5. 
que concurren distintas variables y dependiendo de cómo estas aparezcan o se combinen, la solución a adoptar podrá variar sustancialmente. En estos casos de elevado casuismo el TC utiliza la jurisprudencia del TEDH como ejemplo de las posibles soluciones existentes para cada combinación de elementos: la jurisprudencia del TEDH facilita la labor del TC al ofrecerle una suerte de precedente al que recurrir en aquellos casos en los que no existe una respuesta inequívoca. Por lo general esta forma es utilizada por el TC en asuntos en los que debe resolverse un conflicto entre las libertades de información y expresión y los derechos al honor y a la intimidad; también en casos relativos al derecho al juez imparcial y a la presunción de inocencia.

Mayor intensidad interpretativa presenta la forma que aquí se identifica como la presentación en paralelo del canon constitucional y del canon euro$p_{e o}{ }^{35}$. El resultado de esta forma de presentación del argumento de autoridad es que aparece como parámetro conjunto para valorar la adecuación del acto impugnando al sistema constitucional de derechos fundamentales. Tanto es así que en algunos supuestos, la presentación en paralelo del estándar constitucional y del estándar europeo ha pasado a formar parte de la doctrina del TC de forma que es la combinación de ambos estándares la que conforma el bloque de criterios jurídicos aplicables a una determinada situación. La última forma identificada a través de la que suele exteriorizarse el uso del canon europeo como argumento de autoridad complementario es la guía interpretativa ${ }^{36}$. Esta forma es poco común y es utilizada excepcionalmente por el TC sobre elementos relativos a un derecho fundamental respecto del que existe ya una cierta jurisprudencia constitucional pero que no está suficientemente consolidada. De hecho, en ocasiones puede confundirse, debido a su fuerte incidencia en los argumentos jurídicos del TC, con otra categoría distinta, la incorporación del canon europeo. El elemento que las diferencia es, seguramente, el hecho de que el Tribunal Constitucional utilice el canon europeo como herramienta interpretativa respecto de una línea jurisprudencial ya iniciada por lo que, en este caso, el canon europeo contribuye al desarrollo de aquella. En cambio, la incorporación del canon europeo implica la introducción de un elemento interpretativo o material relativo a un derecho fundamental hasta entonces inexistente en la doctrina constitucional que supone un cambio en su jurisprudencia.

2.2. La incorporación del estándar europeo en el estándar constitucional

Una vez expuestas las distintas formas en las que aparecen las referencias a los instrumentos europeos en su uso como argumento de autoridad pasan a explicarse las dos categorías en las que se produce una auténtica incorpora-

35 Un claro ejemplo de esta forma es la STC 136/1999, F. J. 24.

36 Claros exponentes son la STC 147/1999, F. J. 4, y la STC 41/2001, F. J. 6. 
ción del canon europeo en el canon constitucional, pasando aquel a integrar este último de ahí en adelante. No se trata, al menos no formalmente, de aplicar directamente el CEDH interpretado por el TEDH sino que, más bien, reinterpretar la Constitución de conformidad con la doctrina europea en virtud del mandato del art. 10. 2 CE. En estos casos, pues, el canon europeo desempeña una función integrativa a través de la que se asumen elementos relativos a los derechos fundamentales hasta entonces ignorados por la jurisprudencia constitucional. Además, este tipo de fenómeno cobra mayor trascendencia si tenemos en cuenta que, como se dijo más arriba, la asunción en sentido estricto del canon europeo se produce en sentencias de amparo dictadas por el Pleno del TC. De hecho, es precisamente la necesidad de compatibilizar el estándar constitucional con el estándar europeo el que provoca en la mayoría de casos la reconsideración del criterio jurisprudencial seguido hasta el momento por el Tribunal Constitucional.

Cabe distinguir dos tipos de integración: la asunción de criterios interpretativos y la asunción de contenidos. En cualquiera de los dos supuestos un cambio de rumbo doctrinal motivado por la necesidad de compatibilizar el estándar constitucional de garantía con el estándar europeo supone, por una parte, reconocer el carácter evolutivo del $\mathrm{CEDH}$, que es regularmente actualizado por la jurisprudencia del TEDH, y, por otra, la obligación que implica para los Estados actualizar, asimismo, sus sistemas de forma que sean compatibles con el estándar europeo. A esta tarea contribuye el TC mediante su jurisprudencia cuando modifica sus propios criterios para adecuarlos a los estándares fijados en Estrasburgo. Unas veces la reacción jurisprudencial del TC será rápida y en otras no tanto, debido, en parte, a la necesidad de cambios normativos previos. Por otra parte, la asunción de criterios europeos supone igualmente un paso decidido en favor de la armonización europea en materia de derechos fundamentales, finalidad a la que, como se mostró más arriba, el TEDH contribuye de manera determinante con sus sentencias.

Por último, debe ponerse de relieve que es en este fenómeno de incorporación de contenidos y criterios interpretativos europeos donde se observa una utilización notable del canon europeo no ratificado por el Estado español, fundamentalmente del Protocolo núm. 7 al CEDH, como demuestra la jurisprudencia relativa a la prohibición constitucional de bis in idem y las sentencias dictadas respecto del derecho al doble grado de jurisdicción penal. Esta circunstancia es la que, en parte, ha permitido construir una tercera categoría en los usos que el TC hace del canon europeo: la muestra del desarrollo incipiente de un Ius commune europeo en materia de derechos fundamentales, categoría que será explicada en la parte final de este artículo.

\section{A. Incorporación de criterios interpretativos}

En este caso no se trata de importar nuevas facultades o elementos de los derechos fundamentales no considerados o no aceptados por la jurispruden- 
cia constitucional hasta el momento, sino de adoptar bien una nueva regla interpretativa respecto del análisis de la constitucionalidad de una determinada medida que supuestamente lesiona un derecho, bien una nueva regla de resolución de conflictos entre derechos fundamentales.

Lo cierto es que este tipo de incorporación no es fácilmente identificable pues ya de por sí determinar meridianamente cuales son los métodos interpretativo de un órgano jurisdiccional no es tarea sencilla y, además, en este caso, aparece la dificultad añadida de que los métodos utilizado por el Tribunal Europeo son deudores, en muchos casos, de los métodos utilizados por los Tribunales Constitucionales o Supremos de los Estados parte debido, principalmente, a la subsidiariedad del sistema europeo de garantía ${ }^{37}$. De hecho, la interacción entre jurisdicciones nacionales/constitucionales y europea(s) a la que llevamos asistiendo en las últimas décadas difícilmente permite hablar de orígenes indiscutibles de determinados criterios interpretativos. Sí puede, en cambio, establecerse en la jurisprudencia del TEDH el origen de determinados métodos de análisis interpretativo, sobre todo aquellos que tienen que ver con las restricciones de derechos previstas en los segundos párrafos de los arts. 9, 10 y 11 CEDH: las limitaciones permitidas únicamente serán legítimas si son necesarias en una sociedad democrática y están previstas en una ley.

Pueden ofrecerse dos ejemplos relativos a la asunción constitucional de los criterios europeos lo que no necesariamente deba ser entendido como correcta asunción o aplicación de aquellos. En la STC 2/2003 38 , por ejemplo, puede afirmarse que se produjo un correcto entendimiento del canon europeo relativo al bis in idem. En la citada sentencia el TC invocaba los textos internacionales de referencia en esta materia, que son el art. 14. 7 PIDCP — que se limitaba a transcribir- y el art. 4 Protocolo núm. 7, convertido en referente indiscutible en esta sentencia. En el F. J. 2 el Pleno del Tribunal Constitucional se refería expresamente a su intención de revisar la doctrina constitucional relativa al bis in idem mantenida hasta el momento ${ }^{39}$ y elaboraba un listado de cuales eran los elementos respecto de los que se iba a producir el cambio anunciado:

"la competencia de este Tribunal para revisar el pronunciamiento de los órganos judiciales sobre la existencia de identidad como presupuesto de aplicación de la interdicción constitucional de incurrir en "bis in idem", ya sea sustantivo o procesal, pues la triple identidad delimita el contenido del derecho fundamental -F. 5"; c) «la doctrina sobre la reiteración punitiva — bis- cons-

37 En este sentido, M. A. EISSEN, "L'interaction des jurisprudences constitutionnelles nationales et de la jurisprudence de la Cour Européenne des Droits de l'Homme ", en D. ROUSSEAU Y F. SUDRE, Conseil Constitutionnel et Cour Européene des Droits de l'Homme, París, 1990, p. 140; C. GREWE, Le juge constitutionnel et l'interprétation européenne ", en F SUDRE (dir.), L'interprétation de la Convention européenne des droits de l'bomme, Bruselas, 1998, p. 200.

38 STC $2 / 2003$, de 16 de enero.

39 SSTC 177/1999, de 11 de octubre, y 152/2001, de 2 de julio. Sobre los elementos esenciales de dicha jurisprudencia véanse, J. J. QUERALT JIMÉNEZ, El principio non bis in idem, Madrid, 1992, pp. 9-38, y, 38-55 (selección de jurisprudencia del TC); M. PÉREZ MANZANO, La probibición constitucional de incurrir en bis in idem, Valencia, 2002, pp. 23-42. 
titucionalmente prohibida por el art. 25.1 CE, considerando que la vulneración del derecho fundamental en su vertiente material requiere la efectiva reiteración sancionadora y no basta la mera declaración de imposición de la sanción -F. 6-" d) "la relevancia del órgano sancionador que conoce de los hechos en primer lugar, afirmando la competencia exclusiva de la jurisdicción penal para sancionar en estos casos de concurrencia aparente de infracciones administrativa y penal -F. 9—.

Pues bien, cabe afirmar respecto de los tres elementos mencionados que el TC llevó a cabo una correcta identificación y utilización de los criterios interpretativos utilizados por el Tribunal de Estrasburgo en esta materia. Así, el TC, siguiendo el mismo método que el TEDH, se declaró competente para valorar la existencia de la triple identidad de elementos que debe concurrir para poder hablar, en su caso, de bis in idem. A continuación, el TC incorporó una novedad respecto de su jurisprudencia anterior: para que se produzca la violación del derecho fundamental a no sufrir bis in idem (art. 25. 1 CE) la superposición o adición de sanciones debe ser efectiva. No basta, pues, la mera declaración de imposición de sanción, sino que se exige que el sancionado/condenado haya sufrido materialmente el exceso punitivo que prohíbe el derecho al ne bis in idem. Esta es, precisamente, la línea interpretativa seguida por el TEDH en este tipo de asuntos. Por último la STC 2/2003 ofrece un ejemplo de que el criterio de conformidad con el estándar europeo exigido por el art. 10. 2 CE y por el propio CEDH debe ser entendido como compatibilidad y no como identidad. En este concreto supuesto, el TC se decidió por dotar de prelación al orden penal frente al administrativo, haciendo uso de la facultad de elección reconocida por el TEDH en la sentencia Fischer contra Austria:

"al alcance del derecho reconocido en el art. 4 del Protocolo 7 CEDH, pues el Tribunal Europeo de Derechos Humanos en su Sentencia de 29 de mayo de 2001, caso Franz Fischer c. Austria (pár. 31) ha sostenido que los Estados parte del Convenio europeo de derechos humanos conservan libertad para "regular cuál de las dos infracciones ha de ser perseguidam ${ }^{40}$.

Consecuentemente con la naturaleza subsidiaria del sistema europeo de garantía, en aquellos elementos relativos al alcance de los derechos fundamentales respecto de los que la jurisprudencia del TEDH hubiera permitido un margen de apreciación mayor a los Estados, la compatibilidad se entenderá cumplida con la no oposición de las medidas internas al estándar europeo; en cambio, en aquellos supuestos en los que el margen de actuación de los Estados sea menor o prácticamente inexistente la compatibilidad tiende a la identidad de contendidos. Pues bien, como muestra el fragmento aludido por el TC de la sentencia Franz Fischer contra Austria puede afirmarse que en el aspecto concreto de la determinación de la prelación entre órdenes sancio-

40 STC 2/2003, F. J. 10. 
nadores se reconoce libertad de elección a los Estados ${ }^{41}$. Es compatible, entonces, con el CEDH la solución dada por el TC respecto de la sanción que debe prevalecer en caso de duplicidad sancionatoria administrativa y penal.

Ocurre, en cambio, que en ocasiones el TC atribuye a la doctrina de Estrasburgo un alcance menor, esto es, más restringido que el reconocido verdaderamente por el Tribunal Europeo. Esta situación puede provocar un potencial ataque al CEDH, puesto que el art. 53 de este texto prescribe que la garantía europea nunca podrá aplicarse en detrimento del nivel de garantía reconocido en un ordenamiento jurídico interno y, por tanto, tampoco se permite asumir interpretaciones más restrictivas y, por ende, contrarias al parámetro fijado en Estrasburgo. Esta situación se produjo en la Sentencia de Pleno 49/1999, de 5 de abril, sobre el secreto de las comunicaciones.

La STC 49/1999 suponía, en principio, la incorporación en la jurisprudencia del Tribunal Constitucional de la doctrina contenida en la STEDH caso Valenzuela Contreras contra España, de 30 de julio de 1998. Como es sabido en la sentencia Valenzuela Contreras el TEDH repasaba su doctrina relativa a las garantías que deben concurrir para que una ingerencia en las comunicaciones sea considerada legítima; concretamente: primero, la necesidad de una habilitación legal de la ingerencia, segundo, que aquella ley - formal o material— ${ }^{42}$ sea accesible y previsible. Estas características inherentes a la ley que regula la interferencia en el ejercicio del secreto de las comunicaciones deberán ser especialmente garantizadas en aquellos supuestos en los que la actuación pública se produzca sin conocimiento del titular del derecho, circunstancia que se produce, por ejemplo, en fase de instrucción de determinados delitos. En la sentencia del caso Valenzuela Contreras el TEDH, en aplicación de los citados criterios, declaró vulnerado art. 8 CEDH debido a la falta de calidad de la ley habilitante, sin perjuicio de que el TEDH recono-

41 Puede añadirse que el caso del art. 4 Protocolo núm. 7 debe ser encuadrado en una franja en la que todavía los Estados cuentan con bastante libertad porque, entre otras cosas, así lo permite el propio precepto. Se trata, además, de un Protocolo facultativo al CEDH al que todavía no se han adherido todos los Estados lo que seguramente empuja al TEDH a no marcar unos perfiles excesivamente rígidos para que los Estados aun reticentes acaben ratificándolo y puedan todos estar al nivel exigido desde Estrasburgo. A estas razones, S. HUERTA, «El contenido debilitado del principio europeo de legalidad penal (art. 7 CEDH y art. 4 Protocolo núm. 7", en J. GARCÍA ROCA y P. SANTOLAYA (coords.): La Europa de los Derechos. El Convenio Europeo de Derechos Humanos, Madrid, 2005, p. 482, añade que la jurisprudencia del TEDH respecto del art. 4 Protocolo núm. 7 ha sido hasta el momento bastante comedida en el sentido de que aplica un concepto de bis in idem bastante restrictivo; esta parece ser la postura del propio Tribunal de Estrasburgo: STEDH Göktan contra Francia, pár. 46.

42 A este respecto cabe señalar que el concepto de legislación utilizada por el TEDH en estos supuestos es muy amplio, ya que se toma también en consideración la práctica de los tribunales. En este caso se tomó como referencia, entre otras, el Auto del Tribunal Supremo de 18 de junio de 1992 en un asunto de narcotráfico en el que se había producido a la intervención de las comunicaciones de los encausados. El TS en aquella ocasión, tras reconocer que la legislación de la LECrim era insuficiente, reinterpretó la ley de conformidad con la jurisprudencia del TEDH a este respecto. 
ciera los esfuerzos del juez instructor por garantizar al máximo el derecho al secreto de las comunicaciones, que según el gobierno español suponía anticiparse a las SSTEDH casos Huvig y Kruslin de 1997. En cualquier caso, según el TEDH la actuación judicial no convertía en previsible la normativa legal existente en el momento de los hechos. Así pues, el TEDH consideró insalvable la falta de calidad de la ley señalando esta circunstancia como causa de la violación del art. 8 CEDH.

En 1999 el TC parecía firmemente convencido de la necesidad de incorporar el test sobre la calidad de la ley desarrollado por el TEDH y aplicarlo en el análisis de la normativa española existente en esta materia. Pues bien, tras el examen conjunto de la normativa vigente en el momento de producirse los hechos objeto del recurso de amparo y de los criterios relativos a la calidad de la ley desarrollados por el TEDH y, en concreto, los plasmados en el STEDH caso Valenzuela Contreras, el TC acaba reconociendo que aquella normativa no cumplía con los requisitos mínimos fijados por el TEDH:

«Estamos en presencia de una vulneración del art. 18.3 CE, autónoma e independiente de cualquier otra: la insuficiencia de la ley, que sólo el legislador puede remediar y que constituye, por sí sola, una vulneración del derecho fundamental. Eso es así porque la insuficiente adecuación del ordenamiento a los requerimientos de corteza crea, para todos aquellos a los que las medidas de intervención telefónica pudieran aplicarse, un peligro, en el que reside precisamente dicha vulneración (Sentencia del TEDH caso Klass), ${ }^{43}$.

En definitiva, en la sentencia 49/1999 se reconocía que de conformidad con el estándar europeo el ordenamiento jurídico español padecía una evidente insuficiencia legislativa en materia de secreto de las comunicaciones ${ }^{44}$. Ahora bien, sin perjuicio de este reconocimiento, el TC continuó con el examen del caso, y se centró en el estudio de las garantías que debían acompañar a la autorización, en su caso prórroga, judicial de las escuchas telefónicas. Se producía, así, una incompatibilidad manifiesta entre los criterios interpretativos aplicados por el TEDH en el análisis del respeto de las garantías del derecho al secreto de las comunicaciones y los criterios aplicados por el TC. En efecto, en aquel momento, tal y como demuestra el caso Valenzuela, el TEDH en una situación similar, una vez constatada la insuficiencia legislativa, directamente hubiera pasado a declarar la vulneración del art. 8 CEDH. Esta fue, por cierto, la posición que mantuvo en el asunto Prado Bugallo contra España, de 18 de mayo de 2003. Cierto es también que la responsabilidad primera de adecuar el régimen jurídico de las escuchas en España es del legislador y no del TC; recae sobre el primero la obligación de resultado derivada

43 STC 49/1999, F. J. 5.

44 En la STC 26/2006, F. J. 5, el Tribunal afirmaba que en tanto no exista en España una regulación adecuada al CEDH será suya la función de "suplir las insuficiencias apreciadas en el precepto legal citado hasta que se produzca la necesaria intervención del legisladom. 
del art. 46. $1 \mathrm{CEDH}^{45}$ de modificar la legislación vigente y proceder a la compatibilización con el acquis conventionnel ${ }^{46}$.

Tras la STEDH Prado Bugallo el Tribunal Constitucional resolvió otro asunto relativo a las escuchas telefónica en la STC 184/3003. De nuevo en esta decisión, el Constitucional acudió al examen de la decisión judicial de intervenir las comunicaciones pese a constatar la insuficiencia legislativa en este materia y pese a que el TEDH por dos veces hubiera puesto de manifiesto dicha situación declarando vulnerado el art. $8 \mathrm{CEDH}$. En este caso la coincidencia de criterio respecto de la calidad de la ley fue absoluta, pero, en cambio, los resultados fueron bien distintos.

Sin perjuicio de todo lo expuesto, no debe ocultarse que igual que los hechos causantes de la STC 49/1999 y de la STEDH Prado Bugallo contra España, los hechos de los que traía causa la STC de 2003 eran anteriores al conocidísimo Auto del TS de 1992 sobre el caso Naseiro. Esta coincidencia temporal debe ser destacada porque precisamente el tiempo en que se produjeron los hechos parece ser el punto de inflexión que ha hecho modificar a TEDH sus criterios sobre la calidad de la ley española en materia de escuchas telefónicas. En efecto, el TEDH, en la decisión de inadmisibilidad del asunto Abdulkadir Coban contra Españ $a^{47}$, parece haber reconocido que el art. 579 LECrim, tras la modificación de $1988^{48}$, completado por la jurisprudencia del TS —iniciada con el Auto TS de 1992, caso Naseiro ${ }^{49}$ - y la jurisprudencia del TC, sintetizada en la STC 49/1999 (así lo dice el TEDH), respecto de las garantías que deben cumplirse en toda intervención legítima de las comunicaciones hacen las veces de habilitación legal cierta y previsible respecto de aquellas interceptaciones de las comunicaciones producidas parece que con posterioridad a 1992. Así pues, cabe entender que a partir de ahora, aquellos asuntos que lleguen a Estrasburgo relativos a las escuchas telefónicas que traigan causa de hechos acaecidos con posterioridad al Auto de 1992 serán inadmitidos en aquello que afecte a la calidad de la ley como garantía del derecho al secreto de las comunicaciones. A este respecto cabe criticar que el TEDH haya llevado a cabo

45 Según la doctrina mayoritaria toda sentencia del Tribunal de Estrasburgo estimatoria genera una obligación de resultado al Estado demandado, así, P. A. FERNÁNDEZ SÁNCHEZ, Las obligaciones de los Estados en el marco del Convenio Europeo de Derechos Humanos, Madrid, 1987, p. 73 y ss.; R. RYSSDAL, RYSSDAL, R.: "The enforcement system set up under the European Convention on Human Rights", en M. K. BULTERMAN y M. KUIJER (ed.), Compliance with judgments of international courts: proceedings of the symposium organized in honour of professor Henry G. Schermers, Mordenate College and the Department of International Public Law of Leiden University, La Haya-Boston, 1996, p. 51. Recientemente entre nuestra doctrina, cfr. L. M. DIEZPICAZO GIMÉNEZ, Sistema de derechos fundamentales, 2. ${ }^{a}$ ed., Madrid, 2005, p. 157; F. J. RODRÍGUEZ PONTÓN, La articulación de las garantías administrativas y jurisdiccionales en el sistema del CEDH, CIZUR Memor, 2005, p. 30.

46 Adaptación al castellano de la expresión utilizada por F. SUDRE, Droit Européen et nternational des droits de l'homme, París, $6{ }^{a}$ ed. refondue, 2003, "puesta en compatibilidad".

47 Decisión de inadmisibilidad de 25 de septiembre de 2006, Sección Quinta.

48 Ley Orgánica 4/1988, de 25 de mayo.

49 Auto de 18 de junio de 1992, Sala Segunda del TS. 
este cambio de parecer jurídico en una decisión de inadmisibilidad, y no en una sentencia de Sala desestimatoria en la que se hubiera puesto de manifiesto expresamente el inicio de una nueva línea jurisprudencial en esta materia. El TEDH antepone en ocasiones sus problemas estructurales, esto es la acumulación de demandas, a la calidad y claridad de su jurisprudencia, circunstancia que no escapa a las críticas de algunos sectores doctrinales ${ }^{50}$.

\section{B. Incorporación de contenidos}

La asunción del estándar europeo puede generar dos resultados distintos: en unos casos, la incorporación del estándar europeo provocará el descubrimiento de una facultad o dimensión relativa a un derecho fundamental reconocido en la Constitución no exteriorizada hasta el momento. En otras ocasiones, la recepción del estándar europeo supone, más bien, el reconocimiento de nuevas garantías a través de un giro jurisprudencial provocado por la asunción del canon europeo.

La línea divisoria entre ambos fenómenos, incluso entre estos fenómenos y el de incorporación de criterios interpretativos, no es en absoluto de fácil identificación. Es cierto que el encuadrar una sentencia del TC en una subcategoría o en otra ayuda a entender las influencias del canon europeo en la jurisprudencia constitucional. Ahora bien, lo que realmente subyace a todas ellas y es esta, por ello, la conclusión en mayúsculas de estas páginas, es que sea una nueva facultad, una nueva dimensión, una nueva garantía o una nueva interpretación lo cierto es que la modificación en la jurisprudencia constitucional se debe a la asunción por el TC de los criterios utilizados por el Tribunal de Estrasburgo en sus sentencias.

Entrando en el análisis concreto de los casos estudiados y utilizándolos como muestra de la forma en la que el TC usa el canon europeo, respecto del periodo estudiado cabe afirmar que se ha producido una correcta adopción del canon europeo en la STC 167/2002 relativa a las garantías de inmediación y contradicción en segunda instancia penal. En esta sentencia el TC reconocía que la razón para modificar su doctrina anterior era la necesidad de adaptar más estrictamente la interpretación constitucional del derecho fundamental a un proceso con todas las garantías (art. 24.2 CE) al art. 6. $1 \mathrm{CEDH}$ según ha sido interpretado por la jurisprudencia del Tribunal Europeo de Derechos Humanos.

Hasta la STC 167/2002 de Pleno, el TC había considerado, no sin algún punto de inflexión ${ }^{51}$, que la valoración de la prueba en segunda instancia po-

50 Sobre la importancia de mantener una jurisprudencia de calidad, véase, por todos, J. P. COSTA, J-P. : "La Cour européenne des droits de l'homme : vers un ordre juridique européenne ?", en VV. AA. : Mélanges en Hommage à Luis Edmond Pettiti, Bruselas, 1998, p. 203 ; especialmente críctico es J. CALLEWAERT en su trabajo, "La Convention Européenne des droits de l'homme entre effectivité et prévisibilité", en VV.AA.: Les droits de l'homme au seuil du troisième millénaire. Mélanges en hommage à Pierre Lambert, Bruselas, 2000, pp. 93-108.

51 Por ejemplo, Auto 220/1999, de 20 se septiembre. 
día producirse sin la participación de la persona absuelta o condenada en primera instancia. En cambio, en la jurisprudencia del TEDH viene siendo una constante desde la STEDH caso Ekbatani contra Suecia, de 26 de mayo de 1988 , que el derecho a un proceso con todas las garantías exige que en la segunda instancia penal se celebre una nueva audiencia de los interesados en aquellos supuestos en que el Tribunal competente deba entrar a conocer de cuestiones de Derecho y de hecho y, en su caso, proceder a una apreciación global sobre la inocencia/culpabilidad de la persona condenada/absuelta en primera instancia. Así, si el Tribunal ad quem tiene capacidad para valorar de nuevo los hechos probados en primera instancia el TEDH exige que la nueva valoración de la prueba se practique de nuevo ante aquel, lo que supondrá escuchar al acusado/condenado como mínimo, pero no sólo, ya que también puede ser que el Tribunal ad quem considere necesario que ante él se practiquen otras pruebas, como las declaraciones de testigos o peritos. Por otra parte, los criterios fijados por la jurisprudencia del TEDH se aplican igualmente en aquellos supuestos en los que tras una sentencia absolutoria en primera instancia, en apelación el Tribunal competente dicta una sentencia condenatoria, como sucedió, por ejemplo, en el asunto Constantinescu contra Rumania, sentencia de 27 de junio de 2000. Este era, precisamente, el supuesto de hecho que había dado lugar al recurso de amparo resulto por la STC 167/2002. Así pues, desde la citada sentencia constitucional el respeto de la inmediación y la contradicción en segunda instancia a través de la celebración de una vista oral en la que el juez valore, como mínimo, las pruebas personales de manera directa es una garantía propia del derecho a un proceso con todas la garantías en aquellos supuestos en los que el Tribunal ad quem entre a valorar la inocencia o culpabilidad del condenado/absuelto en primera instancia.

En otras ocasiones el TC atribuye a la jurisprudencia del TEDH un alcance que no se corresponde con el realmente reconocido por aquel a un determinado derecho. La situación no resulta preocupante cuando la falta de correspondencia se produce por exceso ya que puede considerarse que independientemente de esta circunstancia existe una relación de compatibilidad entre estándares. Tal situación se produjo en la STC 91/2000, relativa a las garantías en la extradición del condenado en rebeldía. En esta sentencia el TC llevó a cabo una interpretación de las garantías del art. 6 CEDH más exigente que la establecida por el TEDH. Mientras que la jurisprudencia del TEDH muestra que lo esencial es garantizar el derecho de defensa, ejercida en persona o bien mediante un letrado, según el TC la barrera de lo permisible por el derecho a un proceso con todas las garantías está en garantizar en algún momento que el acusado/condenado pueda personarse ante un juez y que este, en su presencia, revise de nuevo los hechos ${ }^{52}$.

Como ejemplo de una supuesta incorporación del canon europeo en el canon constitucional se ofrece la STC 119/2001. En esta sentencia el TC afirmaba 
haber incorporado una nueva dimensión del derecho a la intimidad desarrollada por el TEDH que supone el reconocimiento de que determinados elementos medioambientales puedan vulnerar los derechos fundamentales del art. 18 CE. Sin embargo, el estudio de esta sentencia constitucional y de otras dictadas con posterioridad pone de manifiesto que el Tribunal Constitucional introdujo en el canon europeo incorporado un elemento suplementario en el test de constitucionalidad aplicado en el control de la actividad del poder público que no es requerido en el test de convencionalidad aplicado por el TEDH, el daño efectivo en la salud del perjudicado, que grava doblemente la situación de las víctimas de estas vulneraciones. En efecto, se obliga a las personas afectadas, primero, a demostrar que efectivamente se producen niveles excesivos de ruido, y, segundo, a demostrar la causalidad entre los ruidos excesivos y un daño efectivo en su salud ${ }^{53}$. De esta forma, toda la carga de la prueba recae sobre la víctima de la supuesta vulneración del derecho a la intimidad. Por el contrario, el TEDH centra su análisis en la comprobación de la actitud de la Administración pública responsable. Primero, lleva a cabo una aproximación objetiva a las circunstancias del caso y, una vez constatados los ruidos excesivos, verifica cuales son las obligaciones de la Administración y cual fue su actuación. Comprueba el incumplimiento de la Administración y da por cerrado el asunto. No exige nexos de causalidad entre ruidos y daños alegados; sólo comprueba si las autoridades públicas han cumplido con sus deberes objetivos de control sobre las actividades que provocan las inmisiones.

Como podrá entenderse, la supuesta incorporación del canon europeo en la STC 119/2001 contrariaba, además, el art. 10. 2 CE y podía convertirse potencialmente en una violación del CEDH - como efectivamente puso de manifiesto una vez más el TEDH en las sentencia Moreno Gómez contra España de $2004^{54}$ - ya que no se llevó a cabo una interpretación compatible con el Convenio Europeo, en tanto que no se respetó el estándar mínimo establecido por Estrasburgo. El TC introdujo un elemento en el test de compatibilidad con los derechos fundamentales de la Constitución que restringía el derecho del particular o, dicho de otra forma, establecía un requisito que gravaba la situación del particular frente a la Administración pública.

2.3. Muestras del desarrollo incipiente de un ius commune europeo en materia de derechos fundamentales

Se ha mencionado ya que entre la doctrina europea la opinión mayoritaria es que todavía hoy no existe un ius commune europeo en materia de de-

53 En este caso, el Tribunal Constitucional no reconoció suficiente prueba de la existencia de los ruidos el hecho de que la calle de la demandante hubiera sido declarada por el Ayuntamiento, entre otras, Zona Acústicamente Saturada.

54 STEDH de 16 de noviembre de2004. 
rechos y libertades. La mayoría de autores coinciden, igualmente, en considerar que sí empiezan a aparecer ya algunos elementos claves en la elaboración del Derecho Común europeo ${ }^{55}$. A esta tendencia es sin duda sensible nuestro Tribunal Constitucional que ha plasmado en sus sentencias su consideración respecto del canon europeo como estándar mínimo europeo y la identificación de aquel canon como la opinio communis europea en materia de derechos fundamentales. Otra muestra más de esa sensibilidad a favor de la armonización en materia de derechos y libertades se materializa en el uso como instrumentos interpretativos que el TC ha hecho de los conceptos autónomos desarrollados por el TEDH en su jurisprudencia.

\section{A. El canon europeo como estándar mínimo común en Europa}

Como se acaba de mencionar el TC reconoce explícitamente en sus sentencias, por lo menos respecto de algunas materias, que la jurisprudencia del TEDH debe ser considerada como el estándar mínimo aplicable en materia de derechos y libertades. Así se ha encargado de reiterarlo el TC, por ejemplo, en sus decisiones relativas a dilaciones indebidas, materia en la que se produce el fenómeno de reiteración de estructuras argumentativas explicado más arriba y que, por tanto, provoca que el reconocimiento del CEDH y la jurisprudencia del TEDH como estándar mínimo europeo sea una afirmación bastante recurrente ${ }^{56}$.

55 Así, por ejemplo, M. DE SALVIA, "L'élaboration d'un " ius commune " des droits de l'homme et des libertés fondamentales dans la perspective de l'unité européenne : l'ouvre accomplie par la Commission et la Cour européennes des Droits de l'Homme ", en F. MATSCHER, y H. PETZOLD (eds.): Protecting human rights: the European dimension: studies in honour of Gérard J. Wiarda. Protection des droits de l'homme: la dimension européenne: mélanges en l' de Gérard J. Wiarda, Colonia, 2. ${ }^{a}$ ed, 1990, p. 556, en 1990 advertía como a través de la jurisprudencia de los órganos de control europeos empezaban a tomar forma los contornos del ius commune europeo, principalmente debido a lo que este autor denominó el efecto didáctico de las sentencias del TEDH, expresión equivalente a la utilizada en este trabajo de función desarrolladora de la jurisprudencia del TEDH, plasmada claramente por el TEDH en su sentencia Irlanda contra Reino Unido de 1978. En cualquier caso, la doctrina mayoritariamente reconoce que los Estados parte del CEDH han reconocido que todos ellos comparten una serie de valores y creencias comunes respecto del respeto y garantía de los derechos y libertades de las personas, cuya salvaguardia han dejado en manos del TEDH; en este sentido, por ejemplo, G. COHEN-JONATHAN, " La CEDH... ", op. cit, p. 391, y, entre nosotros, F. RODRÍGUEZ PONTÓN, F. J.: La articulación..., op. cit., p. 31.

56 Por ejemplo, STC 58/1999, F. J. 6:

"Desde tales premisas este Tribunal ha fijado los términos en los que deben enjuiciarse los retrasos judiciales en coincidencia con la jurisprudencia del Tribunal Europeo de Derechos Humanos sobre el art. 6.1 del Convenio de Roma (derecho a que la causa sea oída en «un tiempo razonable"), que ha sido tomada como el estándar mínimo garantizado en el art. 24.2 CE [STEDH...]. Siguiendo dicha doctrina...".

Igual afirmación aparece, por ejemplo, en las SSTC 124/1999, 230/1999 y 220/2004, todas ellas relativas a la violación del derecho a no sufrir dilaciones indebidas. 
Esta idea de estándar común mínimo ha sido igualmente explicitada en varias sentencias relativas a los procesos de extradición pasiva, por ejemplo la STC 87/2000, F. J. 5, y ha cobrado un especial relevancia en la STC 91/2000 a la que se aludió más arriba. En esta sentencia el TC se hacía eco de la doctrina de los efectos ad extra de los derechos fundamentales desarrollada desde sus inicios por el TEDH. Admitida la virtualidad extraterritorial del alcance de los derechos fundamentales, el TC advierte que no todos los derechos constitucionales o, mejor dicho, no todas las facultades o posiciones jurídicas de estos derechos pueden ser vulnerados indirectamente, sino que sólo aquellos que formen parte del contenido absoluto del derecho que se define, fundamentalmente, a través de su inherencia a la dignidad humana. En ese proceso de determinación - expresión utilizada literalmente por el TC- de los derechos inherente a la dignidad de la persona, revisten especial relevancia «la Declaración Universal de Derechos Humanos y los demás tratados y acuerdos internacionales sobre las mismas materias ratificados por España, a los que el art. 10.2 CE remite como criterio interpretativo de los derechos fundamentales". Y, dentro de los tratados internacionales a los que se ha reconocido la importante función hermenéutica de determinar el contenido de los derechos fundamentales, goza de una situación "singular [e]l Convenio Europeo de Derechos Humanos, dado que su cumplimiento está sometido al control del Tribunal Europeo de Derechos Humanos, a quien corresponde concretar el contenido de los derechos declarados en el Convenio que, en principio, ban de reconocer, como contenido minimo de sus derechos fundamentales, los Estados signatarios del mismo, 57 .

De la lectura de las líneas trascritas se extraen como mínimo las cuatro conclusiones siguientes: en Europa existe una comunidad que comparte unos valores e intereses, entre los que está la protección de los derechos fundamentales; por ello, los tratados internacionales, a través del art. 10. 2 CE, sirven para determinar cual es el contenido de aquellos derechos compartidos por todos en aquella comunidad y que es pues el contenido mínimo e irrenunciable; el CEDH es especialmente relevante por la existencia del TEDH, que lo desarrolla y actualiza; el bloque de convencionalidad formado por el CEDH y la jurisprudencia del TEDH suponen el contenido mínimo de los derechos fundamentales que deben respetarse en todos los Estados parte.

Se confirma de esta forma el carácter privilegiado del que gozan el CEDH y principalmente la jurisprudencia del TEDH en la determinación del contenido de los derechos constitucionales a través de su interpretación. Igualmente, el párrafo trascrito supone una clara prueba del reconocimiento explícito de que el desarrollo jurisprudencial que el Tribunal de Estrasburgo ha hecho de los derechos y libertades del CEDH se erige en el estándar mínimo común europeo. 


\section{B. Muestra de la opinio communis europea en materia de derechos fundamentales}

El TC expresamente ha tomado el acquis conventionnel compuesto por el CEDH y la jurisprudencia del TEDH como el reflejo de la opinión común europea acerca del estado de los derechos fundamentales. Así, por ejemplo, en la STC 116/1999, que resolvía el recurso de inconstitucionalidad contra la Ley 35/1988 sobre Técnicas de Reproducción Asistida ${ }^{58}$, al hilo de la discusión sobre la idea de familia amparada por la Constitución, el TC afirmaba que:

«[...] quizá la prueba más palpable de esa necesaria diferenciación de planos y, por ende, de la autonomía de significado que adquiere el instituto de la familia en su concepción estrictamente jurídica, lo constituya el hecho comúnmente aceptado de que los hijos adoptivos se integren y constituyan una familia, aunque sus padres legales no se correspondan con los biológicos (véanse, en este sentido, las Sentencias del TEDH de 13 de junio de 1979 (asunto Marckx) 26 de mayo de 1994 (asunto Keegan v. Irlanda) y la de 27 de octubre de 1994 (asunto Catharina Kroon, Ali Zerrouk y Sami M'Hallem-Driss v. Países Bajos). No existe, por lo tanto, una obligada correspondencia entre las relaciones paterno-filiales jurídicamente reconocidas y las naturales derivadas de la procreación (SSTC 289/1993 y 114/1997) ni, como queda dicho el concepto constitucional de familia se reduce a la matrimonial (SSTC 184/1990 y $222 / 1992), 59$.

Aunque en referencia al Estatuto del Consejo de Europa, merece la pena citar la STC $73 / 2000^{60}$, F. J. 11:

"Sentado lo anterior podemos ya pasar a considerar si se produce una lesión del art. $24.1 \mathrm{CE}$, en los supuestos aquí considerados, esto es, aquéllos en los que los efectos obstativos de una Ley o del régimen jurídico en ella establecido para una concreta materia fuese, precisamente, el de hacer imposible que un determinado fallo judicial se cumpla. Pues aun siendo indudable que la Constitución reconoce al legislador un amplio margen de libertad al configurar sus opciones, no es menos cierto que también le somete a determinados límites. Y en lo que aquí interesa, no sólo al genérico límite antes aludido de la interdicción de la arbitrariedad de los poderes públicos (art. 9.3 CE) y al que impone al principio de igualdad (art. $14 \mathrm{CE}$ ) sino también al límite que se deriva del art. 24.1 CE. Lo que se corresponde, como antes se ha dicho, con la importancia que posee el

58 Concretamente, por la supuesta vulneración de los artículos 9, 10, 15, 39 y 81 de la CE. 59 STC 116/1999, F. J. 13.

60 STC de Pleno en la que se resolvía una cuestión de inconstitucionalidad planteada por la Sala de lo contencioso-administrativo de la Audiencia Nacional en relación con varios preceptos de la Ley Foral de Navarra 9/1996, de Espacios Naturales Protegidos de dicha Comunidad, en lo que afectaban a la presa de Itoiz. La cuestión se planteó por presunta vulneración del principio de interdicción de la arbitrariedad de los poderes públicos y del derecho fundamental a obtener la tutela efectiva de Jueces y Tribunales en su vertiente de ejecución de las resoluciones judiciales firmes; el TC desestimó la cuestión. 
logro de una tutela judicial efectiva y el cumplimiento de las resoluciones judiciales firmes en un Estado de Derecho como el que ha configurado nuestra Constitución en su art. 1.1 y constituye, además, patrimonio común con otros Estados de nuestro entorno europeo - art. 3 en relación con el art. 1 a) del Estatuto del Consejo de Europa, hecho en Londres el 5 de mayo de 1949—.

Como puede observarse, el TC toma como referente del patrimonio común europeo el Estatuto del Consejo de Europa. Como es sabido, el Convenio de Roma en 1950 fue elaborado precisamente como instrumento para la realización del Estado de Derecho común a las sociedades democráticas que conforman el Consejo de Europa.

Tal es el convencimiento del TC sobre el hecho de que el acquis conventionnel es la muestra de la opinio communis del estado de los derechos fundamentales en Europa que ha tomado también como referente europeo textos no ratificados todavía por el Estado español, concretamente, el Protocolo adicional núm. 7 al Convenio. Es más, ha utilizado este texto no ratificado en detrimento de otros textos internacionales relativos a los mismos derechos sí ratificados por el Estado español, concretamente el PIDCP. Y, todavía más, el Protocolo núm. 7 ha sido el responsable del cambio de rumbo jurisprudencial respecto, por ejemplo, del derecho a no padecer bis in idem, cambio realizado, como se dijo más arriba, en una sentencia del Pleno del Tribunal Constitucional. ¿Cuál es el motivo que lleva al Tribunal Constitucional ha dejar de lado el PIDCP, aquí su art. 14. 7, para utilizar el art. 4 Protocolo núm. 7? La respuesta la ofrece propio TC: dicho Protocolo "constituye un adecuado marco de referencia en cuanto expresivo de un modelo jurídico-constitucional común en nuestro entorno".

Desde la perspectiva europea, este modelo jurídico-constitucional está integrado por el CEDH, todos los Protocolos adicionales al CEDH y la jurisprudencia del TEDH. Todos estos instrumentos conforman, pues, el acquis conventionnel por lo que a todos afecta la obligación general que deriva del CEDH y que subyace al sistema de protección europeo de compatibilizar los estándares nacionales con el estándar europeo, más allá de las obligaciones concretas impuestas por las cláusulas constitucionales de apertura internacional respecto de la utilización de los textos ratificados como herramientas hermenéuticas. El sistema europeo de garantía de los derechos fundamentales ha cobrado tal importancia y tal fuerza en los últimos años que la obligación derivada del art. 46 $\mathrm{CEDH}$ puesta en relación con el deber general del art. $1 \mathrm{CEDH}$ se han convertido en una obligación de resultado que supera las previsiones internas relativas a la interpretación conforme. Estas, en su caso, ayudan a la compatibilización pero no son, por lo que demuestra la realidad, indispensables ${ }^{61}$.

61 En 2004, el TC dictó la sentencia 169/2004, F. J. 3, en relación al derecho a no padecer bis in idem, en la que se refiere expresamente a la falta de ratificación del Protocolo núm. 7 al $\mathrm{CEDH}$, sin conceder a este hecho mayor relevancia respecto de la posibilidad de utilizarlo como canon interpretativo en virtud del art. 10. 2 CE: 
Tanto es así que el TC se siente legitimado, incluso, para escoger el referente europeo en detrimento del internacional que le ofrece le PIDCP en una materia tan importante como es el derecho al doble de grado de jurisdicción ${ }^{62}$. Las sentencias dictadas a este respecto ${ }^{63}$ suponen un supuesto específico en tanto que ponen de manifiesto como el estándar internacional, compuesto por el PIDCP - texto ratificado por España- y la labor jurisprudencial del Comité de Derechos Humanos, es prácticamente ignorado por el $\mathrm{TC}^{64}$ en favor del

"El elemento de la firmeza de la Sentencia impeditiva de la celebración de un nuevo juicio se destaca en los textos internacionales que ex art. 10.2 CE deben operar como elemento interpretativo de los derechos fundamentales, como es el caso del art. 14.7 del Pacto internacional de derechos civiles y políticos, de 16 de diciembre de 1966 ( RCL 1977, 893), y del art. 4.1 del Protocolo núm. 7 del Convenio europeo para la protección de los derechos humanos y de las libertades fundamentales, de 22 de noviembre de 1984, suscrito, aunque no ratificado por España. De modo que no existe impedimento constitucional de principio para que una Sentencia penal absolutoria, si la legalidad infraconstitucional lo permite, pueda ser objeto de recurso de apelación, para que por ello pueda ser anulada en la apelación y para que consecuentemente pueda celebrarse un segundo juicio penal respecto del acusadon (cursiva añadida).

62 Los problemas respecto del derecho al doble grado de jurisdicción reconocido en el art. 14. 5 PIDCP se han producido en situaciones en las que el demandante absuelto en primera instancia fue condenado en segunda instancia, sin que cupiera posterior recurso contra dicha condena. Muy polémica es, igualmente, la cuestión relativa a la casación penal que, como es sabido, es un medio de impugnación extraordinario que persigue la anulación de la decisión judicial recurrida; únicamente puede ser interpuesto por una serie de motivos tasados que responden a la existencia de vicios en la aplicación o interpretación de las normas de Derecho material o procesal. Así pues, en principio a través del recurso de casación no cabe aducir cuestiones de hecho. Por último, también ha planteado problemas de compatibilidad con el estándar internacional la circunstancia de que los aforados, y aquellos incursos en sus mismas causas, no tengan derecho a la revisión de una potencial condena dictada por el Tribunal Supremo en única instancia.

63 STC 120/1999 (Sala 2. ${ }^{a}$ ), STC 133/2000 (Sala 1. ${ }^{a}$ ), STC 91/2002 (Sala 2. ${ }^{\text {) }}$, STC 64/2001 (Pleno), STC 65/2001 (Pleno), STC 66/2001 (Pleno), STC 70/2002 (Sala 1. ${ }^{\text {a)}) ; ~ r e c i e n t e m e n t e, ~ e s t a ~}$ doctrina ha sido reiterada respecto del recurso penal de casación en la STC 123/2005 (Pleno) y en la STC $116 / 2006\left(\right.$ Sala $\left.1 .^{\mathrm{a}}\right)$.

64 La STC 116/2006 es una excepción a la actitud mantenida por el TC hasta la fecha. En esta sentencia de 2006 el TC hizo una recopilación de algunos de los más recientes dictámenes del Comité de Derechos Humanos para reforzar su postura relativa a la compatibilidad de la casación penal prevista en nuestro ordenamiento jurídico con el art. 14. 5 PIDCP. Aunque no es ahora el momento de hacer un análisis exhaustivo de las decisiones del Comité citadas por el TC sí cabe señalar que, pese a lo que se deriva del F. J. 6 de la STC 116/2006, no puede afirmarse tajantemente que el Comité de Derechos Humanos haya modificado su criterio respecto de la casación penal española; los Dictámenes dictados por el Comité en los años 2005 y 2006 se limitan a reconocer que en los casos concretamente estudiados el Tribunal Supremo había realizado una valoración de la prueba suficientemente detallada y no se había quedado únicamente en el análisis de las cuestiones jurídicas (por ejemplo, caso Carvallo Villar contra España, de 21 de noviembre de 2005; caso Oubiña Piñeiro contra España, de 11 de agosto de 2006). Por otra parte, no debe olvidar el TC que si bien en los casos citados el Comité de Derechos Humanos ha reconocido una actuación del Tribunal Supremo en casación conforme con el art. 14. 5 PIDCP, en otros Dictámenes relativos al derecho al doble grado de jurisdicción sigue recordando que las condenas penales dictadas en segunda instancia también deben poder ser sometidas a una revisión integral en la que se estudien las cuestiones de hecho (por ejemplo, caso Gomariz Valera contra España, de 26 de agosto de 2005; caso García Sánchez y González Clares contra España, de 15 de noviembre de 2006). 
estándar europeo conformado por el Protocolo núm. 7 al CEDH, pese a no haber sido ratificado por el Estado español, porque resulta mucho más "comprensivo" con el régimen español en materia de doble grado de jurisdicción. En efecto, la doctrina coincide en admitir que del art. 14. 5 PIDCP y de los dictámenes elaborados por el Comité de Derechos Humanos se deriva el reconocimiento del derecho a la doble instancia, que exige que ante el Tribunal superior se lleve a cabo un nuevo juicio ${ }^{65}$; en cambio, de la jurisprudencia del TEDH y del propio redactado del art. 2. 1 Protocolo núm. 7 se deriva la exigencia de que la decisión condenatoria dictada por el juez de instancia sea revisada por un Tribunal superior, siendo libre el legislador nacional para determinar los supuestos, requisitos y concretos medios de impugnación existentes para cada resolución ${ }^{66}$. Por último, el Protocolo núm. 7 excluye una serie de decisiones condenatorias del ámbito del derecho al doble grado de jurisdicción: la condena dictada en segunda instancia contra la absolución del juez a quo y la condena dictada en única instancia por el más alto órgano jurisdiccional del Estado ${ }^{67}$.

Quizá debería recordar el Tribunal Constitucional lo que él mismo tantas veces y con tanta vehemencia ha puesto de relieve: el CEDH y la jurisprudencia del TEDH se erigen en estándar mínimo europeo. Este mínimo que deberá ser garantizado en todos los Estado parte del CEDH puede ser, obviamente, superado. De hecho podría incluso afirmarse que una interpretación conforme con el art. 14. 5 PIDCP y con los Dictámenes del Comité de Derechos Humanos llevarían a dotar de un mayor nivel de garantía al derecho a la doble instancia en España. En este caso, podría llegarse a la conclusión de que el art. 10. $2 \mathrm{CE}$ en tanto que obliga al TC a interpretar los derechos de la Constitución de conformidad con los textos internacionales ratificados por el Estado español, provoca que el derecho a la doble instancia pueda gozar en

65 A. SAIZ ARNAIZ, "El derecho fundamental al recurso en el orden penal y la interpretación del artículo 24. 1 CE de conformidad con el Derecho internacional y europeo de los Derechos humanos (especial referencia a la situación de los aforados y a los supuestos de conexidad): un ejemplo de desafortunada jurisprudencia constitucional", REDEur, enero-marzo, núm. 5, 2003, pp. 123-157.

66 Veáse ARANGÜENA FANEGO, C.: "El derecho al doble grado de jurisdicción en el orden penal", en J. GARCÍA ROCA y P. SANTOLAYA (coords.): La Europa de los Derechos. El Convenio Europeo de Derechos Humanos, Madrid, 2005, p. 255. Igualmente, así lo explicita la propia jurisprudencia del TEDH, por ejemplo, en su sentencia caso Müller contra Austria, de 5 de octubre de 2006.

A este respecto también debe tenerse en cuenta el Informe Explicativo redactado por el Comité de expertos que elaboró el Protocolo núm. 7 que reconoce en su pár. 18 libertad a los Estados para decidir si el recurso debe implicar el conocimiento de cuestiones de hecho, de Derecho o de ambos aspectos de la causa; esta ambigüedad ha sido criticada por distintos autores véase, por todos, P. VAN DIJK Y G. J. H. VAN HOOF, Theory and practice of the European Convention on Human Rights, La Haya, 1998, p. 686.

67 El Comité de Derechos Humanos ha reiterado su posición respecto de la falta de compatibilidad con el art. 14. 5 PIDCP del régimen previsto en nuestro ordenamiento para el enjuiciamiento de los delitos cometidos por los aforados en su Dictamen Oliveró Capellades contra España, de 8 de agosto de 2006. 
España de una protección mayor a la reconocida por el Protocolo núm. 7 al $\mathrm{CEDH}$ y la jurisprudencia del TEDH; dicho de otro modo, si el TC hace uso del mandato del art. 10. 2 CE y utiliza el PIDCP y los dictámenes del Comité, el nivel de protección del derecho a la doble instancia será mayor que el reconocido actualmente. Partiendo de esta premisa, el propio CEDH, mediante lo previsto en su art. 53, estaría prohibiendo a lo tribunales españoles optar por una herramienta hermenéutica - el Protocolo núm. 7 y la correspondiente jurisprudencia del TEDH - que limita el (potencial) mayor alcance de la garantía de un determinado derecho fundamental. Este tipo de casos, sin embargo, no pueden a día de hoy llegar al conocimiento del TEDH porque la utilización del Protocolo núm. 7 por la jurisdicciones españolas, al no haber sido ratificado por España, no es susceptible de control europeo.

\section{Los conceptos autónomos del canon europeo}

El CEDH es un instrumento jurídico vivo y, aunque influenciado por ellos, autónomos del devenir de los sistemas internos de garantía. Esta realidad queda plasmada en el fenómeno de los conceptos autónomos. Sabemos que el CEDH es aplicado por el TEDH respecto de todos los Estados parte con ordenamientos y tradiciones jurídicas muy diversos y que, además, en cada uno de estos Estados el CEDH es aplicado por gran variedad de autoridades; es más, el propio sistema de garantía parte y acepta la heterogeneidad sobre la que construye. Pues bien, la utilización por el TEDH de los conceptos autónomos ha favorecido determinantemente el fenómeno de la armonización del estándar europeo en este escenario heterogéneo ya que aquellos permiten dotar de un contenido y alcance propio a los elementos configuradores de los derechos y libertades convencionales, con independencia de cual sea su reconocimiento (en ocasiones, inexistencia) y alcance en los sistemas internos de garantía. Además, el recurso de los conceptos autónomos evita una aplicación desigual del CEDH en los territorios que abarca, y, garantiza, a la postre, la efectividad del sistema ${ }^{68}$.

La técnica de los conceptos autónomos son una muestra de la función jurisprudencial del TEDH de interpretar y desarrollar el CEDH de forma auténtica; en este caso, el TEDH dota de un contenido concreto a determinadas fórmulas o conceptos abiertos que pasan a formar parte del $\mathrm{CEDH}$. En este caso puede afirmarse, sin duda, que el significado del CEDH queda establecido por el TEDH y que es ese significado el que las autoridades nacionales de todos los Estados parte deben otorgar a los distintos preceptos convencionales cuando se dispongan a aplicar el CEDH o cuando lo utilicen como instrumento interpretativo de su propio catálogo de derechos fundamentales. Todo

68 P. VAN DIJK Y G.J.H. VAN HOOF, Theory and practice..., op. cit., p. 77, nota a pie núm. 17. 
ello independientemente de quien fuera el Estado demandado en el asunto en cuestión. Cuando el TEDH reconoce un contenido propio a un determinado término del CEDH tal actuación afecta a las autoridades nacionales de todos los Estados parte porque, como se acaba de decir, el TEDH es el intérprete auténtico del CEDH. Así lo muestra la práctica del propio TEDH que para utilizar y aplicar a los conceptos de tribunal, derechos y obligaciones civiles, ley, etc., recogidos en el CEDH se remite a su propia jurisprudencia ${ }^{69}$. La consideración de los conceptos autónomos como integrados en el propio CEDH lo demuestra igualmente la práctica de los tribunales internos quienes, al referirse al CEDH y al significado de su texto toman como auténtico el contenido dotado por el TEDH a la fórmula o concepto en cuestión. Es más, en ocasiones, las jurisdicciones internas utilizan los conceptos autónomos como referentes incontestables, en tanto que aceptados comúnmente en el entorno europeo, para la interpretación de sus propios catálogos de derechos. Prueba de ello es, sin duda, el uso normal que el Tribunal Constitucional español hace de estos conceptos.

\section{CONSIDERACIONES FINALES}

Los resultados expuestos en las páginas anteriores sobre la participación del Tribunal Constitucional en el proceso de armonización europeo en materia de derechos fundamentales permiten ofrecer algunas consideraciones finales desde una doble perspectiva, europea e interna.

Desde una perspectiva europea, cabe afirmar que si bien la actitud de TC responde en principio al cumplimiento del mandato de interpretación conforme del art. 10. 2 CE, sin embargo, la utilización que el TC realiza de textos europeos no ratificados por España y la jurisprudencia del TEDH que los desarrolla es una nueva demostración de que del art. $1 \mathrm{CEDH}$ deriva una obligación general de interpretación conforme, entendiendo conformidad como compatibilidad, que hace posible el proceso europeo de armonización en materia de derechos y libertades fundamentales. Esto viene a coincidir con la postura adoptada por otros Tribunales Constitucionales europeos que utilizan el canon europeo como instrumento interpretativo de sus propios catálogos de derechos sin que exista en sus respectivos ordenamientos una cláusula de apertura internacional como la prevista por el art. 10. 2 CE.

Desde la perspectiva interna, se ha mostrado como el Tribunal Constitucional utiliza el canon europeo como instrumento interpretativo de manera ordinaria. El canon europeo es utilizado como argumento de autoridad y como fuente de criterios interpretativos y de nuevas facultades y garantías de los de-

69 STEDH Weeks contra Reino Unido, de 2 de marzo de 1987, respecto del concepto "tribunal" del art. 5. 4 CEDH (pár. 61); STEDH Stubbings y otros contra Reino Unido, de 22 de octubre de 1996, respecto del concepto de respeto de vida privada (pár. 61); otros muchos ejemplos podrían ser ofrecidos. 
rechos fundamentales reconocidos en la Constitución. De hecho, el canon europeo es en ocasiones el responsable de los cambios jurisprudenciales que aparecen en las sentencias de Pleno en los recursos de amparo. Así pues, desde la dimensión interna sí puede afirmarse que el art. 10. 2 CE ha provocado que el test de compatibilidad con el canon europeo pueda entenderse integrado en el análisis de constitucionalidad - no siempre explícitamenteque el Tribunal Constitucional utiliza en sus decisiones. En definitiva, quizá haya llegado el momento de reconocer que el CEDH y la jurisprudencia del TEDH forman parte de una suerte de bloque de constitucionalidad en materia de derechos fundamentales formado por la Constitución, por la jurisprudencia del TC y por el acquis conventionnel. Desde luego, esto es lo que se deduce de la práctica jurisdiccional del Tribunal Constitucional.

ABSTRACT. It is an incontestable fact that domestic judges use the Strasbourg case law as an interpretative tool when applying the Convention or even its own catalogue of rights; however, it is still necessary to establish the real impact of the European jurisprudence. This article seeks to show how the case law of the Spanish Constitutional Court has been influenced by the European canon. With this aim the work exposes the main conclusions achieved through the exhaustive analysis of the Constitutional judgements delivered from 1999 to 2004. This study relies on a proposal of categorisation of the interpretative uses given by the Constitutional Court to the European canon. Each of the categories provides by itself enough evidence of the participation of our Constitutional Court in the harmonization process lead by the Strasbourgh Court in the great Europe. 